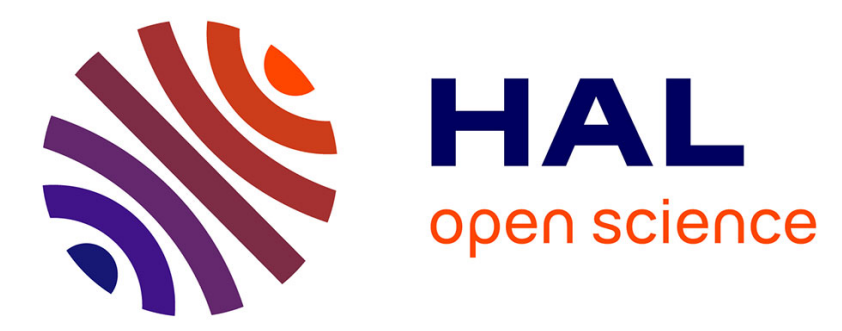

\title{
Optimal sizing of distributed generation in gas/electricity/heat supply networks
}

Bei Li, Robin Roche, Damien Paire, Abdellatif Miraoui

\section{To cite this version:}

Bei Li, Robin Roche, Damien Paire, Abdellatif Miraoui. Optimal sizing of distributed generation in gas/electricity/heat supply networks. Energy, 2018, 151, pp.675 - 688. hal-02131089

\section{HAL Id: hal-02131089 \\ https://hal.science/hal-02131089}

Submitted on 16 May 2019

HAL is a multi-disciplinary open access archive for the deposit and dissemination of scientific research documents, whether they are published or not. The documents may come from teaching and research institutions in France or abroad, or from public or private research centers.
L'archive ouverte pluridisciplinaire HAL, est destinée au dépôt et à la diffusion de documents scientifiques de niveau recherche, publiés ou non, émanant des établissements d'enseignement et de recherche français ou étrangers, des laboratoires publics ou privés. 


\title{
Optimal sizing of distributed generation in gas/electricity/heat supply networks
}

\author{
Bei $\mathrm{Li}^{\mathrm{a}, \mathrm{c}, *}$, Robin Roche ${ }^{\mathrm{a}, \mathrm{c}}$, Damien Paire ${ }^{\mathrm{a}, \mathrm{c}}$, Abdellatif Miraoui ${ }^{\mathrm{b}, \mathrm{c}}$ \\ ${ }^{a}$ FEMTO-ST, CNRS, Univ. Bourgogne Franche-Comte, UTBM, rue Thierry Mieg, F-90010 Belfort Cedex, France \\ ${ }^{b}$ Univ. Bourgogne Franche-Comte, UTBM, rue Thierry Mieg, F-90010 Belfort Cedex, France \\ ${ }^{c}$ FCLAB, CNRS, Univ. Bourgogne Franche-Comte, rue Thierry Mieg, F-90010 Belfort Cedex, France
}

\begin{abstract}
Multi-energy supply systems are expected to play an important role in smart grids. Today's energy supply systems are large nodes networks, and different types of energy are needed at each node to satisfy the different energy demands. These different types of energy can then be converted to each other through specific devices. How to decide the ratings of these devices at each node to make the system cost-effective is addressed in this paper. The focus is set on a gas/electricity/heat hybrid network. A hydrogen storage system (fuel cell, electrolyzer, and tanks) is used as electricity storage system, a combined heat and power device is used to produce heat and electric power, etc. A mixed integer linear programming algorithm is used to determine the optimal operation schedule of the system, where the goal is to minimize shed load. A genetic algorithm is also used to search for the best size of each component, where the goal is to minimize the total investment costs. In order to resist to contingency events, betweenness centrality (describing the relative importance of each node) is then used to find the worst case under contingency events. This worst case scenario is used to research about the influence of contingencies on the sizing results. At last, two cases (modified 13-node network and IEEE $30+$ Gas 20 + Heat 14 nodes system) are tested using the proposed sizing method. The results show that the renewable energy location, investment cost of components, and the structure of the whole system influence the sizing results. When the installed capacity of photovoltaic panels is reduced by $50 \%$, the capacity of the electrolyzer decreases by $3 \%$, the capacity for the hydrogen tanks increases by $2 \%$; when the investment cost of the fuel cell and electrolyzer decreases by $50 \%$, the capacity of photovoltaic increases by $14 \%$, the electrolyzer increases by $13 \%$, and hydrogen tanks increase by $2 \%$. After considering the worst case contingency event, for case I, the capacity of photovoltaic and fuel cell increase by $12 \%$ and $11 \%$, and the electrolyzer increases by $34 \%$; for case II, the capacity of photovoltaic and fuel cell increase by $8 \%$ and $11 \%$, and the electrolyzer increases by $57 \%$.
\end{abstract}

Keywords: sizing, multi-energy system, gas/electricity/heat, hydrogen storage system, optimization

\section{Nomenclature}

\section{Acronyms}

3 CCHP combined cooling heat and power

4 CHP combined heat and power

DG distributed generation

EA evolutionary algorithm

EH energy hub

8 GA genetic algorithm

MG microgrid
12

${ }_{13} \alpha \quad$ penalty values for load shedding of gas demands

${ }_{14} \beta \quad$ penalty values for load shedding of electricity demands

${ }_{15} \gamma \quad$ penalty values for load shedding of heat demands

${ }_{16} C_{\text {inv }}$ investment cost of each component

$17 e f f_{C H P}$ gas utilization efficiency of CHP to consume gas

${ }_{18} e f f_{c h}$ efficiency to produce $\mathrm{H}_{2}$ through the electrolyzer

$19 e f f_{E T H}$ efficiency of ETH to produce heat

$20 e f f_{G T H}$ efficiency of GTH to produce heat

$21 e f f_{\text {heat }}$ fuel cell efficiency to produce heat

$22 \quad e f f_{r e}$ heat recovery efficiency of $\mathrm{CHP}$

${ }_{23} \quad L_{e l}^{i, t} \quad$ electricity load demands at node $i$ and time $t$ (MW)

24 $\quad L_{\text {gas }}^{i, t} \quad$ gas load demands at node $i$ and time $t$ (MW)

$25 L_{\text {heat }}^{i, t} \quad$ heat load demands at node $i$ and time $t$ (MW)
${ }^{*}$ Corresponding author.

Email addresses: bei.li@utbm.fr (Bei Li), robin.roche@utbm.fr (Robin Roche), damien.paire@utbm.fr (Damien Paire), abdellatif.miraoui@utbm.fr (Abdellatif Miraoui) 


$$
\begin{aligned}
& { }_{26} \quad P_{\text {line }}^{\text {el,m,n,max }} \text { maximum electricity power flow from } m \text { to } n \\
& { }_{27} \quad P_{\text {line }}^{\text {gas,m,n,max }} \text { maximum gas power flow from } m \text { to } n \\
& { }_{28} \quad P_{\text {line }}^{\text {heat, }, n, \text { max }} \text { maximum heating power flow from } m \text { to } n
\end{aligned}
$$

\section{Variables}

30 $\quad C_{g s}^{i} \quad$ capacity of $\mathrm{H}_{2}$ storage tanks at node $i(\mathrm{MWh})$

${ }_{31} \quad L S_{e l}^{i, t} \quad$ load shedding of electricity demands at node $i$ and time ${ }_{65}$ $32 \quad t$

3з $L S_{\text {gas }}^{i, t}$ load shedding of gas demands at node $i$ and time $t$

${ }_{34} L S_{\text {heat }}^{i, t}$ load shedding of heat demands at node $i$ and time $t$

${ }_{35}$ onof $f_{\text {ele }}^{i, t}$ ON/OFF state of the electrolyzer at node $i$ and time $t_{7}^{7}$

36 onof $f_{f c}^{i, t}$ ON/OFF state of the fuel cell at node $i$ and time $t$

${ }_{37} P_{C H P}^{i, m a x} \quad$ capacity of a CHP at node $i(\mathrm{MW})$

${ }_{38} \quad P_{\text {ele }}^{i, \max }$ capacity of a electrolyzer at node $i(\mathrm{MW})$

39 $\quad P_{E T H}^{i, m a x} \quad$ capacity of an ETH at node $i(\mathrm{MW})$

${ }_{40} P_{f c}^{i, \max }$ capacity of a fuel cell at node $i(\mathrm{MW})$

${ }_{41} P_{G T H}^{i, m a x} \quad$ capacity of a GTH at node $i$ (MW)

${ }_{42} P_{\text {line }}^{e l, m, n, t}$ electricity power flow from node $m$ to node $n$ at time $t{ }_{86}$

${ }_{43} P_{\text {line }}^{\text {gas, } m, n, t}$ gas power flow from node $m$ to node $n$ at time $t$

${ }_{44} P_{\text {line }}^{\text {heat }, m, n, t}$ heating power flow from node $m$ to node $n$ at time $t$

${ }_{45} \quad P_{P V}^{i} \quad$ capacity of a PV source at node $i(\mathrm{MW})$

${ }_{46} S_{g s}^{i, t} \quad$ state of the $\mathrm{H}_{2}$ storage tanks at node $i$ and time $t$

${ }_{47} Z_{C H P}^{i, t} \quad$ output power of the CHP at node $i$ and time $t$

${ }_{48} Z_{e l e}^{i, t} \quad$ output power of the electrolyzer at node $i$ and time $t$

${ }_{49} Z_{E T H}^{i, t} \quad$ output power of the ETH at node $i$ and time $t$

50 $Z_{f c}^{i, t} \quad$ output power of the fuel cell at node $i$ and time $t$

${ }_{51} Z_{G T H}^{i, t}$ output power of the GTH at node $i$ and time $t$

${ }_{52} Z_{P S}^{e l, i, t} \quad$ output power of the electric generator at node $i$ and ${ }_{106}$ 53 time $t$

${ }_{54} Z_{P S}^{g a s, i, t}$ output power of the gas source at node $i$ and time $t$

${ }_{55} Z_{P S}^{\text {heat }, i, t}$ output power of the heating source at node $i$ and time $t_{111}$

\section{Introduction}

Today's energy supply systems mostly consist of large transmission networks, such as the electricity network and gas supply network. Normally, these energy supply networks are planned separately. Load demands often include several types of energy in the same time step. For example, when people use gas to cook, they also need electricity to serve electronic devices, and heat energy to heat the room. These large energy supply systems can co-operate together to improve the efficiency of the whole energy supply system. Co-operating can indeed make the whole system operate in an optimal state, while ensuring the power balance of different energy supplies. The main interest of this approach is that at each interconnection node, different types of energy can be converted to each other through power devices. For example, fuel cells can be used to convert $\mathrm{H}_{2}$ to electricity, electrolyzers can be used to convert electricity to $\mathrm{H}_{2}$, gas turbines can be used to convert gas to heat, etc. At each node, renewable energy can also be connected, such as with photovoltaic (PV) panels and wind turbines.

This paper intends to contribute to addressing the following problem: how to determine the ratings of these power devices and renewable energy sources at each interconnection node, based on a given multi-energy network topology? In this work, a modified 13-node network is considered, and three types of gas/electricity/heat load demands are served. The selected electricity network is the IEEE 13-node network [1], and the gas and heating networks are assumed to have the same structure, as shown in Fig. 1). In this figure, HS represents a hydrogen storage system (fuel cell, electrolyzer and tanks), which has several advantages, such as a high storage capacity, and a high energy per unit of volume [2]; CHP is a combined heat and power device; ETH is a device that converts electricity to heat, a heat boiler for example; GTH is a device that converts gas to heat, a gas boiler heater for example. Black lines represent the gas supply system, blue lines the electricity supply system, and red lines the heat supply system.

At each node, the devices and load demands can be formed as a microgrid (MG) or an energy hub (EH). In [3], authors design a combined cooling/heat/power and hydrogen MG system, and present a combined genetic algorithm (GA) and mixed integer linear programming (MILP) method to size such multi-energy supply MG. GA is used to search for the sizing values, MILP is used to control the operation of MG. In [4], authors present a smart EH framework to deploy an integrated demand response program (considering electricity and natural gas demands). The goal is to maximize the natural gas and electricity utility companies' profit and to minimize the customers' consumption cost. The problem is formulated as a non-cooperative game.

For MG, the emphasis is on islanded operation ability, which can improve the system resilience when the utility grid is damaged under natural disasters. Authors in [5] use gas-based and hydrogen-based MG to improve resilience to disasters. A hybrid energy supply (electricity/gas/hydrogen) system is built, and Monte Carlo simulation is used to simulate the influence of disasters. For EH, the emphasis is on the energy dispatching efficiency, which can reduce the waste of fuel and improve the 


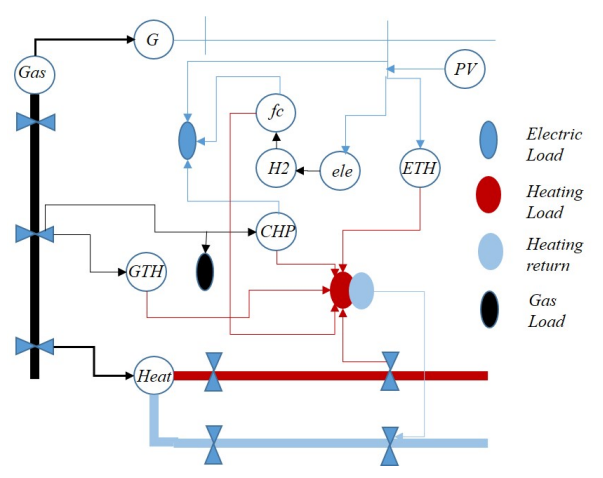

Figure 2: Microgrid structure at each node.

energy utilization efficiency, or act as a load serving entity to 138

In this paper, renewable energy is integrated and an MG is 140

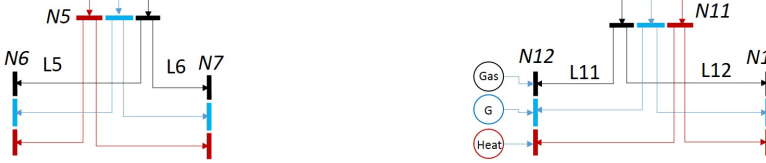

Figure 1: Gas/electricity/heat network structure.

$$
154
$$

A multi-energy MG can interconnect with the utility grid, 171 and can also operate in islanded mode. When the utility grid ${ }_{172}$ is severely damaged under natural disasters, the islanded $\mathrm{MG}_{173}$ can still operate to supply the load demands using the local re-174 newable energy and the storage systems. If the utility grid is 175 partially destroyed, the MG power imports from the utility grid ${ }_{176}$ are limited, due to damage on transmission lines or pipelines.177 This paper discusses how such large power devices and PV pan-178 els should be installed and sized in each MG. A combined al-179 gorithm is presented to size the components in MG to resistiso to contingency events (namely, some transmission lines are de-181 stroyed). Firstly, an optimization method is used to describe the 182 power flow in the whole system, where the objective function ${ }_{183}$ is to minimize the investment cost and the unserved load. The 184 constraints are to ensure the power balance and meet capacity 185 limitations. Then, a GA is used to search for the optimal sizing 186 value of each component. After that, two cases are simulated:187 the first case is a modified 13-node hybrid system, and the sec-188 ond case is a IEEE20 + gas 20 + heat14-node hybrid system. 189 Graph theory is used to find the worst case based on between-190 ness centrality, when the electric system is damaged under con-191 tingency events.

The remainder of this paper is organized as follows. Section 2 introduces related work. Section 3 describes the problem formulation, and Section 4, 5 the simulation results. Finally, Section 6 concludes the paper.

\section{Related work}

In this section, related works about the optimal sizing problem of multi-energy supply systems are presented. This problem includes two aspects: 1) the operation problem, which describes the power flow in the whole system; 2) the sizing problem, which determines the sizing values of each component.

\subsection{Operation problem}

To decide the sizing values of each component, firstly, one needs to describe the operation of the whole system. Many works have been done about the optimal operation of multienergy supply system. The operation problem is often described as a mixed integer programming problem.

In [6], authors present a mixed integer nonlinear programming (MINLP) model for short-term 24-h scheduling of an $\mathrm{EH}$, in which the objective is to fulfill the daily cooling/heating/electric demands with maximum profit. [7] presents a mathematic model for the operational schedule of residential energy supply (electricity and heat) based on microgeneration. The objective function is to minimize the total cost. Results show that the microgeneration-based energy supply system overwhelms other counterparts (boiler systems, standalone operation). [8] presents a smart home energy management model, which is formulated as an MILP problem. The objective is to minimize the overall energy cost as well as peak demand from the main grid. The appliance consumption cycle is initiated based on its starting probability, and a new discomfort index is proposed, which is defined as the load deviation from the most desired load. [9] presents a short-term scheduling problem of single domestic-size microgrids. The problem is described as an MILP model and extended to a unit commitment problem. Two time models are compared: a discrete time model and a hybrid time formulation model. In the discrete time-based model, decisions related to energy production and consumption are taken at the beginning of each time interval. In the hybrid time representation model, energy production decisions are the same as in the previous model, but the decisions related to energy consumption can be taken continuously. Further, authors in [10] present a 30-minute scheduling approach for electricity and heat demands in a microgrid. Delays in the starting times and eventual interruptions during the performance of tasks are allowed to exploit the benefits of flexibility in the energy demand. The problem is formulated as an MILP problem to minimize the operation costs of the microgrid. [11] presents a multi-objective energy management algorithm to schedule the consumption in smart homes. The two conflicting objectives are to minimize the daily energy cost and $\mathrm{CO}_{2}$ emissions. The model is described as an MILP problem. The $\epsilon$-constraint method is used to solve the multi-objective optimization problem. 
The above papers discuss the operation problem of EH, res-248 idential supply, smart homes and microgrids. Some variables 249 need to be considered, such as on/off states (binary variables) 250 and output/input powers (continous variables), which makes251 the problem challenging. MILP problems consider both bi-252 nary and continous variables and can be solved using a linear 253 programming-based branch-and-bound algorithm [12]. The op-254 timal scheduling set points are determined based on current and $_{25}$ future conditions, which can guarantee obtaining the global op-256 timal results.

\subsection{Sizing problem}

Many works have also been presented about the optimal siz-260 ing and siting of distributed generation (DG) in electric power 26 systems. [13] reviews classical and heuristic approaches for 262 optimal sizing and placement of DG units in distribution net-263 works. In [14], DG allocation problems are reviewed from 264 the viewpoint of the used optimization algorithms, objectives,265 decision variables, DG type, applied constraints, and kind of 266 uncertainty models. Papers show that metaheuristic-based ap-267 proaches are effective in solving the DG allocation problem and 268 are the most common approaches for solving this problem, but 269 these approaches may converge into false local optima rather 270 than the global optimum.

In [15], authors propose an independent system operator 272 (ISO) model for coordinating transmission expansion planning 273 with competitive generation capacity planning in electricity 274 markets. The security-constrained planning problem consists275 of three problems: transmission capacity planning (maximizing 276 the investment profits), security assessment (minimizing real 277 power mismatch at each bus) and optimal operation (maximiz-278 ing the revealed surplus based on submitted bids for genera-279 tion, demand, and incremental transmission). At last, a modi-280 fied IEEE 30-bus system is used to evaluate the method. [16 $]_{281}$ presents an algorithm for microgrid planning as an alternative 282 to the co-optimization of generation and transmission expan-283 sion planning in electric power systems. The problem is de-284 composed into a planning problem and an annual reliability285 subproblem. When the annual reliability limits are violated,286 the planning decisions are revised using proper feasibility cuts.287 The method is tested on a modified IEEE 118-bus system. In 288 [17], authors present a microgrid planning model. This problem 289 is decomposed into an investment master problem and an oper-290 ation subproblem. These problems are linked via the benders291 decomposition method. [18] describes an approach to address 292 the microgrid expansion planning problem. The master prob-293 lem is to maximize the profit of individual investors, the second 294 layer problem is to check the reliability criteria, and the third 295 layer problem is to minimize the operation cost. The proposed 296 method is examined on a four-bus test system. [19] presents297 an electric expansion planning approach, which includes three 298 options for network expansion as generating units (i.e., wind,299 solar, and diesel), ESS, and lines. The problem is described as 300 a two-level MINLP problem, where the first level is to mini-301 mize the planning cost, and the second level is to minimize the 302 operation cost. Both problems are solved by a hybrid meta- 03 heuristic optimization technique which collects the benefits of ${ }_{304}$ particle swarm optimization (PSO), cultural algorithm, and coevolutionary algorithms at the same time.

The above papers use co-optimization methods to solve the microgrid planning problem. This method decomposes the planning problem into a master problem and a subproblem which can consider two time scales: long term planning and short term operation. The master problem aims to search for the planning results, and the subproblem is to evaluate the correctness of the operation problem. In this paper, the sizing problem of multi-energy supply system is similar to the planning problem, which can be solved effectively by the co-optimization method.

Some works about the sizing problem of multi-energy microgrids have also been published. In [20], authors present an MILP model for the optimal design of DG systems coupled with heating, cooling, and power distribution networks, aiming to minimize the annual overall cost. In [21], authors present a deterministic linear programming model to obtain the optimal size of a residential combined heat and power (CHP) plant, and the objective function is to minimize the annual cost of the system. A constant ratio is used to represent the relation between electricity output and heat output. In [22], a multiobjective MINLP model is formulated for the simultaneous system synthesis, technology selection, unit sizing, and operation optimization of a large scale combined cooling heat and power (CCHP) system. The objective function is to minimize the total annual cost and the annual global $\mathrm{CO}_{2}$ emissions. The augmented $\epsilon$-constraint method is applied to determine the Pareto frontier of the design configuration. [23] presents a two-stage optimal planning and design method for a CCHP MG system. In the first stage, a multi-objective genetic algorithm based on NSGA-II is applied to solve the optimal design problem. The objective function is to minimize the total net present cost and carbon dioxide emissions. In the second stage, an MILP algorithm is used to solve the optimal dispatching problem, where the objective function is to minimize the operation cost. [24] presents a multi-objective optimization approach based on GA for a CHP system within an MG. The two objectives are to minimize the total cost and the total gas emissions from the main grid, boiler and DG units. The operation strategies are 'following electrical load' and 'following thermal load'.

Works about the co-planning of natural gas and power electric systems are also researched. In [25], an integrated electricity and natural gas transportation system planning algorithm is proposed for enhancing the power grid resilience in extreme conditions. The first stage problem is to minimize the investment and the operation costs for the integrated electricity and natural gas. The second stage problem is to minimize load curtailment after the occurrence of the most severe event. The test results on the IEEE RTS1979 system point out that the integrated planning of electricity and natural gas can improve power system resilience. [26] proposes a longterm co-optimization planning model which incorporates natural gas infrastructure planning with power system planning. The investment problem is formulated to optimally determine appropriate candidates for generating units, transmission lines, and natural gas pipelines. The second subproblem is the power 
system feasibility and optimality (minimizing the load curtail-360 ment). The third subproblem is the natural gas transportation ${ }_{361}$ feasibility (minimizing the nodal natural gas load imbalance). At last, the power system reliability is evaluated. [27] proposes 363 an integrated expansion planning framework for gas and power 364 systems. The model aims to maximize the benefit/cost ratio 365 by calculating benefits in operation reduction, carbon emissions ${ }_{366}$ reduction and reliability improvement against augmentation in-367 vestment costs. [28] presents a long term, multiarea, and multistage model for supply/interconnections expansion planning of ${ }^{368}$ an integrated electricity and natural gas system. The proposed ${ }^{369}$ model is formulated as an optimization problem, which mini- ${ }^{370}$ mizes the investment and operation costs to determine the op- ${ }^{371}$ timal location, technologies, and installation times of any new ${ }^{372}$ facility for power generation, power interconnections, and the ${ }^{373}$ complete natural gas chain value (supply/transmission/storage) ${ }^{374}$ as well as the optimal dispatch of existing and new facilities ${ }^{375}$ over a long range planning horizon.

As shown by the above papers, the co-planning method $\mathrm{can}^{377}$ consider the characteristics of the power system and the nat- ${ }^{378}$ ural gas system at the same time, which includes the interac- ${ }^{379}$ tions between both systems on supply and demand sides, and ${ }^{380}$ help achieve higher market efficiency in the cost benefit analy- ${ }^{381}$ sis [27].

Based on the above researches on electric power system ex- ${ }^{383}$ pansion planning, sizing problems of multi-energy microgrids, ${ }^{384}$ and co-planning of gas/electricity systems, some conclusions can be drawn: 1) for the design problem, the time horizon ranges from 18 months to 10 years, or even more, and for ${ }^{385}$ the planning problem, the time horizon is from 1 month to $18_{386}$ months; 2) the planning results must be checked for the operation problem feasibility, with a short time scale and usually $\mathrm{a}_{388}$ 1-h resolution; 3) the uncertainty on load demand, output of renewable energy and contingency events (such as line damage, ${ }_{390}$ natural disasters, etc.) must also be considered.

The following shortcomings can be highlighted concerning the previous studies in the field of multi-energy supply system planning:

1. The previous approaches considered the uncertainty on load demand, output of renewable energy, but do not consider contingency events (such as line damage, natural disasters, etc.).

2. For a multi-energy supply system, the interconnection structure of different types of energy systems must also be considered, because it can influence the energy flow in the whole system, which will then influence the utilization of the power devices, and at last, the planning results will be different.

However, research works about the sizing problem of gas/electricity/heat hybrid systems have not been given a lot of attention so far. [29] researched about the sizing problem of an electricity/heat system, and showed that a single-node ag-394 gregate approach (namely, ignore the interconnection structure 395 inside the microgrid) cannot capture the internal energy trans- 396 fers and the limitations of the electrical/thermal networks.
In our previous paper [30], a co-optimization method combining an evolutionary algorithm (EA) and MILP was used to size a full-electric islanded microgrid. Next, in [3], this method was used to size a multi-energy supply microgrid considering the degradation of hydrogen storage system. In this paper, the co-optimization method is adopted to provide a sizing solution for a hybrid gas/electricity/heat network. The main contributions of this paper are as follows:

1. A multi-node gas/electricity/heat network model is presented, where a hydrogen storage system is used to keep the power balance;

2. An MILP model is used to control the operation of the whole system, and is combined with an EA to solve the sizing problem;

3. Network theory, namely, betweenness centrality, is used to describe the relative importance of nodes;

4. The most important node is destroyed, as the worst case scenario to research about the influence of contingencies on the sizing results;

5. The method is tested on two multi-energy networks (a 13node hybrid network and a IEEE30 + gas 20 + heat14-node network), and shows that the renewable energy location, investment cost of components, and the structure of the whole system influence the sizing values of each component.

\section{Problem formulation}

The proposed sizing problem approach can be summarized with the diagram shown in Fig. 3. The sizing problem returns the sizing values of each component, and then these values are used to test the correct operation of the system. Based on the results of the operation problem, new sizing values are updated, and this process is repeated until the stopping criterion is satisfied. In this paper, the stopping criterion is the maximum iteration number of GA.

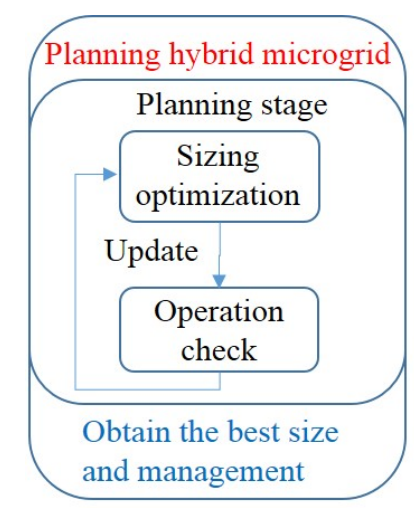

Figure 3: Sizing problem approach diagram.

Assume that a hybrid multi-energy supply network contains $N$ nodes, and at each node $i=1, \ldots, N, \mathrm{PV}$ panels are connected. The capacity of a PV source at each node is noted $P_{P V}^{i}$; a fuel cell is used to convert $\mathrm{H}_{2}$ energy to electricity and the capacity 
of the fuel cell at each node is $P_{f c}^{i, \text { max }}$; an electrolyzer is used to ${ }_{421}$ convert electricity to $\mathrm{H}_{2}$ and the capacity of an electrolyzer at 422 each node is $P_{e l e}^{i \text { max }} ; \mathrm{H}_{2}$ storage tanks are used to store $\mathrm{H}_{2}$ and ${ }_{423}$ the capacity of $\mathrm{H}_{2}$ storage tanks at each node is $C_{g s}^{i}$; an ETH device is used to convert electricity to heat and the capacity of an ETH at each node is $P_{E T H}^{i, m a x}$; a GTH is used to convert gas energy to heat and the capacity of GTH at each node is $P_{G T H}^{i, m a x}$; a CHP device is used to produce heat and power and the capacity of CHP at each node is $P_{C H P}^{i, m a x}$. In short, the goal of the proposed method is to decide the sizing or capacity values of the above components.

\subsection{Operation problem}

For the operation problem, the goal is to minimize the $\operatorname{load}^{427}$ shedding of gas/electricity/heat demands, and ensure the relia- ${ }^{42}$ bility of the whole system. The objective function can then be written as:

$$
\begin{aligned}
C_{o p}^{\text {all }}= & \alpha \cdot \sum_{i=1}^{N} \sum_{t=1}^{T} L S_{\text {gas }}^{i, t}+\beta \cdot \sum_{i=1}^{N} \sum_{t=1}^{T} L S_{\text {el }}^{i, t} \\
& +\gamma \cdot \sum_{i=1}^{N} \sum_{t=1}^{T} L S_{\text {heat }}^{i, t}
\end{aligned}
$$

where $\alpha, \beta$, and $\gamma$ are penalty values for load shedding of gas/electricity/heat demands, and $L S_{g a s}^{i, t}, L S_{e l}^{i, t}$ and $L S_{\text {heat }}^{i, t}$ are the load shedding of gas/electricity/heat demands at node $i$ and time $t$.

The power devices constraints are:

$$
\begin{aligned}
& -P_{\text {line }}^{\text {gas, }, n, \text { max }} \leq P_{\text {line }}^{\text {gas, }, n, t} \leq P_{\text {line }}^{\text {gas, }, n, \max } \\
& -P_{\text {line }}^{\text {el,n,max }} \leq P_{\text {line }}^{\text {el,m,n,t}} \leq P_{\text {line }}^{e l, m, n, \max } \\
& -P_{\text {line }}^{\text {heat, }, n, \text { max }} \leq P_{\text {line }}^{\text {heat, }, n, t} \leq P_{\text {line }}^{\text {heat, }, n, \text { max }} \\
& \text { onoff } f_{f c}^{i, t} \cdot P_{f c}^{i, \min } \leq Z_{f c}^{i, t} \leq \text { onoff } f_{f c}^{i, t} \cdot P_{f c}^{i, \max } \\
& \text { onof } f_{\text {ele }}^{i, t} \cdot P_{\text {ele }}^{i, m i n} \leq Z_{\text {ele }}^{i, t} \leq \text { onoff } f_{\text {ele }}^{i, t} \cdot P_{\text {ele }}^{i, \text { max }} \\
& \text { onof } f_{f c}^{i, t}+\text { onoff } f_{\text {ele }}^{i, t} \leq 1
\end{aligned}
$$

$$
\begin{aligned}
& 0 \leq Z_{E T H}^{i, t} \leq P_{E T H}^{i, m a x} \\
& 0 \leq Z_{G T H}^{i, t} \leq P_{G T H}^{i, m a x} \\
& 0 \leq Z_{C H P}^{i, t} \leq P_{C H P}^{i, m a x} \\
& 0 \leq Z_{P S}^{\text {gas,i,t }} \leq Z_{P S}^{\text {gas,i,max }} \\
& 0 \leq Z_{P S}^{\text {el,i,t }} \leq Z_{P S}^{\text {el,i,max }} \\
& 0 \leq Z_{P S}^{\text {heat }, i, t} \leq Z_{P S}^{\text {heat,i,max }}
\end{aligned}
$$

where $P_{\text {line }}^{g a s, m, n, t}$ is the gas power flow from node $m$ to node $n$ at time $t ; P_{\text {line }}^{\text {glas, }, n, \text { max }}$ is the maximum gas power flow from $m$ to $n ; 436$ onof $f_{f c}^{i, t}$ is the ON/OFF state of the fuel cell at node $i$ and time ${ }^{437}$ $t ; P_{f c}^{i, \min }$ and $P_{f c}^{i, \max }$ are the minimum and maximum output of the ${ }^{438}$ fuel cell at node $i ; P_{\text {ele }}^{i, \min }$ and $P_{\text {ele }}^{i, \max }$ are the minimum and maxi- ${ }^{439}$ mum input of the electrolyzer at node $i ; Z_{f c}^{i, t}, Z_{e l e}^{i, t}, Z_{E T H}^{i, t}, Z_{G T H}^{i, t}{ }^{\prime 441}$ and $Z_{C H P}^{i, t}$ are the output power of the fuel cell, electrolyzer,442
ETH, GTH, CHP at node $i$ and time $t ; Z_{P S}^{\text {gas,i,t }}, Z_{P S}^{e l, i, t}$, and $Z_{P S}^{\text {heat }, i, t}$ are the output power of the gas source, electric generator, and heating source at node $i$ and time $t$.

The state of $\mathrm{H}_{2}$ storage tanks can be described as:

$$
S_{g s}^{i, t}=S_{g s}^{i, t-1}+\left(Z_{e l e}^{i, t} \cdot e f f_{c h}-Z_{f c}^{i, t}\right) \cdot \Delta t / C_{g s}^{i}
$$

where $S_{g s}^{i, t}$ is the state of the $\mathrm{H}_{2}$ storage tanks at node $i$ and time $t$, and $\Delta t$ is the time interval. eff $f_{c h}$ is the efficiency to produce $\mathrm{H}_{2}$ through the electrolyzer.

The $\mathrm{H}_{2}$ storage tanks constraint is:

$$
S_{g s}^{i, \min } \leq S_{g s}^{i, t} \leq S_{g s}^{i, \max }
$$

where $S_{g s}^{i, \min }, S_{g s}^{i, \max }$ are the minimal and maximal state of the $\mathrm{H}_{2}$ storage system at node $i$.

For the CHP, the following characteristics are used [31]. First, the power generation:

$$
Z_{C H P}=\alpha^{G E} Q_{C H P}+\beta^{G E} ;
$$

Available waste heat value of flue gas:

$$
q^{G A S}=\alpha^{G A S} Q_{C H P}+\beta^{G A S} ;
$$

Available waste heat value of cylinder water:

$$
q^{W A}=\alpha^{W A} Q_{C H P}+\beta^{W A} ;
$$

Recovery heat from CHP:

$$
q_{C H P}=e f f_{r e} \cdot\left\{q^{G A S}+q^{W A}\right\}
$$

$\alpha^{G E}$ and $\beta^{G E}$ are the coefficient values to generate electricrecovery heat from CHP.

The gas power balance constraint is:

$$
\begin{aligned}
& Z_{P S}^{\text {gass,i,t}}-Z_{G T H}^{i, t} / e f f_{G T H}-Q_{C H P}^{i, t} / e f f_{C H P} \\
& -\left(L_{\text {gas }}^{i, t}-L S_{\text {gas }}^{i, t}\right)=P_{\text {line }}^{\text {gas, } X \rightarrow i, t}
\end{aligned}
$$

The electricity power balance constraint is:

$$
\begin{aligned}
& Z_{P S}^{e l, i, t}+P_{P V}^{i, t}+Z_{f c}^{i, t}+Z_{C H P}^{i, t}-Z_{e l e}^{i, t}-Z_{E T H}^{i, t} \\
& -\left(L_{e l}^{i, t}-L S_{e l}^{i, t}\right)=P_{\text {line }}^{e l, X, t}
\end{aligned}
$$

The heat power balance constraint is:

$$
\begin{aligned}
& Z_{P S}^{\text {heat }, i, t}+e f f_{\text {heat }} \cdot Z_{f c}^{i, t}+e f f_{E T H} \cdot Z_{E T H}^{i, t} \\
& +Z_{G T H}^{i, t}+q_{C H P}^{i, t}-\left(L_{\text {heat }}^{i, t}-L S_{\text {heat }}^{i, t}\right)=P_{\text {line }}^{\text {heat } X \rightarrow i, t}
\end{aligned}
$$

where $P_{\text {line }}^{g a s, X \rightarrow i, t}$ is the gas power flow from node $X$ to $i$ at time $t$, with $X$ representing all nodes that connect with node $i$. $e f f_{G T H}$ is the efficiency of GTH to produce heat; $e f f_{C H P}$ is the gas utilization efficiency of CHP to consume gas; $e f f_{\text {heat }}$ is the fuel cell efficiency to produce heat; $e f f_{E T H}$ is the efficiency of ETH to produce heat. $L_{g a s}^{i, t}, L_{e l}^{i, t}, L_{\text {heat }}^{i, t}$ are the gas/electricity/heat load demands at node $i$ and time $t$. 


\subsection{Sizing problem}

For the sizing problem, the objective is to minimize the total ${ }^{464}$ investment cost. So the objective function can be written as: $\quad{ }^{465}$

$$
\begin{aligned}
& C_{i n v}^{a l l}=\sum_{i=1}^{N}\left\{C_{i n v}^{P V} \cdot P_{P V}^{i}+C_{i n v}^{f c} \cdot P_{f c}^{i, m a x}+C_{i n v}^{e l e} \cdot P_{e l e}^{i, m a x}\right. \\
& +C_{i n v}^{g s} \cdot C_{g s}^{i}+C_{i n v}^{E T H} \cdot P_{E T H}^{i, m a x}+C_{i n v}^{G T H} \cdot P_{G T H}^{i, m a x} \\
& \left.+C_{i n v}^{C H P} \cdot P_{C H P}^{i, \max }\right\}
\end{aligned}
$$

where $C_{i n v}$ is the investment cost of each component.

$\mathbf{U}$ is used to represent the set of the sizing problem variables, ${ }_{471}$ namely, $\mathbf{U}=\left\{P_{P V}^{i}, P_{f c}^{i, \text { max }}, P_{\text {ele }}^{i, \text { max }}, C_{g s}^{i}, P_{E T H}^{i, \text { max }}, P_{G T H}^{i, \text { max }}, P_{C H P}^{i, \text { max }}\right\}$, with $i=1, \ldots, N$. S represents the set of the operation problem variables.

In summary, the sizing problem of the hybrid ${ }_{475}^{474}$ gas/electricity/heat system can be written as follows:

$$
\begin{aligned}
\min _{\mathbf{U}}\left\{C_{\text {inv }}^{\text {all }}+\min _{U^{*}, \mathbf{S}}\left\{C_{o p}^{\text {all }}\right\}\right\} \\
\quad \text { s.t. (2), (3), (4), (5), (6), (7), (8), (9), (10), (11), (12) }
\end{aligned}
$$

\subsection{Considering the contingency events}

In large nodes hybrid networks, contingency events must be considered to maximize reliability. In this section, the influence of contingency events on the sizing results is developed. A large number of contingency events can be listed, and it is impossible to consider all cases. So a robust method can be used to find the worst case. The sizing problem can then be described as follows:

$$
\begin{aligned}
& \min _{\mathbf{U}}\left\{C_{\text {inv }}^{\text {all }}+\underset{\mathbf{V}}{\max } \min _{U^{*}, \mathbf{S}}\left\{C_{o p}^{\text {all }}\right\}\right\} \\
& \quad \text { s.t. (2), (3), (4), (5), (6), (7), (8), (9), (10), (11), (12) }
\end{aligned}
$$

where $\mathbf{V}$ represents the set of contingency events. In other ${ }_{482}$ words, the goal is to search for the best sizing values $U^{*}$ from $_{483}$ $\mathbf{U}$, which can enable the whole system to operate with minimal ${ }_{484}$ costs, and at the same time, ensure that it resists to the worst ${ }_{485}$ contingency event.

For this two stage optimization problem, the column-and- ${ }_{487}$ constraint generation method [32] is used. In [33], authors use ${ }_{488}$ this method to solve a robust MG planning problem. In [34], au- ${ }_{489}$ thors also use this method to solve a distribution network plan- ${ }_{490}$ ning problem to minimize the system damage against natural disasters.

In this paper, the worst case is obtained based on graph theory. For a large nodes hybrid network system, the relative importance of each node is ranked. The case where the most important node is destroyed under the contingency event is the worst case. The relative importance of each node in the graph is described using betweenness centrality [35]:

$$
C_{B}(i)=\sum_{n_{i} \neq n_{k} \neq n_{l}} \frac{n_{k} \rightarrow n_{l}, n_{i}}{n_{k} \rightarrow n_{l}}
$$

where $n_{k} \rightarrow n_{l}, n_{i}$ is 1 if the shortest path between nodes $n_{k}$ to $n_{l}$ goes through $n_{i}$, and 0 if $n_{k}$ to $n_{l}$ does not pass through $n_{i}$. ${ }_{491}$
Under the worst case, the new structure of the whole system can be obtained. Then the sizing problem (14) is solved based on this new structure, and new sizing values can be obtained.

\section{Simulation results for Case I}

In this section, the method is tested on the modified 13-node case. Three sub-cases are compared. For the operation problem, the time step is 1 hour, and the time horizon is one day ( 24 hours).

\subsection{System setup}

The penalty values are arbitrarily chosen as $\alpha=\beta=\gamma=10^{10}$ to make sure that the penalty cost of load shedding is larger than that of the total investment cost. Investment costs are shown in Tab. 1. The cost parameters are adopted from [1, 30]. The model is implemented in MATLAB and solved with YALMIP [36] and Gurobi. Simulations were run on a computer with an Intel Xeon CPU E3-1220@3.1GHz.

Table 1: Investment costs $[1,30]$

\begin{tabular}{lc}
\hline Device & Cost \\
\hline PV & $2 \mathrm{M} € / \mathrm{MW}$ \\
Fuel cell & $4 \mathrm{M} € / \mathrm{MW}$ \\
Electrolyzer & $3.2 \mathrm{M} € / \mathrm{MW}$ \\
$\mathrm{H}_{2}$ tank & $1200 € / \mathrm{MWh}$ \\
ETH & $0.06 \mathrm{M} € / \mathrm{MW}$ \\
$\mathrm{GTH}$ & $0.15 \mathrm{M} € / \mathrm{MW}$ \\
$\mathrm{CHP}$ & $1.6 \mathrm{M} € / \mathrm{MW}$ \\
\hline
\end{tabular}

Load demands (peak load) at each node are shown in Tab. 2. Sources ratings data is shown in Tab. 3. The capacity of lines is shown in Tab. 4, where the unit is $M W$. The efficiency parameters are shown in Tab. 5. Here the capacity of pipelines in the heat network are assumed to be the same as power lines. In order to reduce the computation time, four typical days (spring, summer, autumn, winter) are used as the load block. In each hour of the typical day, the operation problem (minimizing load shedding) is checked based on the sizing problem. If the constraints of the operation problem are violated, then new sizing values are generated. The simulation flow chart can be seen in Fig. 4.

Table 2: Load demand (peak load) [1]

\begin{tabular}{llll}
\hline Bus & $L_{e l}[\mathrm{MW}]$ & $L_{\text {heat }}[\mathrm{MW}]$ & $L_{g a s}[\mathrm{MW}]$ \\
\hline 1 & 4.8334 & 3.8323 & 1.8251 \\
2 & 7.0342 & 6.0123 & 1.0789 \\
6 & 5.1668 & 4.1532 & 1.1652 \\
7 & 5.8746 & 4.8056 & 1.8487 \\
10 & 7 & 6.5642 & 1.0023 \\
12 & 5.1668 & 4.1756 & 1.1695 \\
13 & 4.9254 & 3.9652 & 1.9362 \\
\hline
\end{tabular}

In the following, three cases are compared: 
Table 3: Sources ratings data [1]

\begin{tabular}{llll}
\hline Bus & $Z_{P S}^{\text {el,max }}[\mathrm{MW}]$ & $Z_{P S}^{\text {heat,max }}[\mathrm{MW}]$ & $Z_{P S}^{\text {gas,max }}[\mathrm{MW}]$ \\
\hline 1 & 5 & 4 & 6 \\
8 & 0 & 0 & 90 \\
12 & 8 & 7 & 8 \\
\hline
\end{tabular}

Table 4: Line data [1]

\begin{tabular}{ccc|ccc}
\hline Line & $P_{\text {line }}^{\text {el }}$ & $P_{\text {line }}^{\text {gas }}$ & Line & $P_{\text {line }}^{\text {el }}$ & $P_{\text {line }}^{\text {gas }}$ \\
\hline 1 & 4.9 & 11 & 7 & 23.6 & 50 \\
2 & 7.2 & 15 & 8 & 17.4 & 37 \\
3 & 12.2 & 26 & 9 & 7.2 & 15 \\
4 & 11.6 & 24 & 10 & 10.8 & 22 \\
5 & 5.4 & 11 & 11 & 5.4 & 11 \\
6 & 6.2 & 13 & 12 & 5.4 & 11 \\
\hline
\end{tabular}

Table 5: Efficiency values

\begin{tabular}{cc|cc}
\hline Efficiency & Value & Efficiency & Value \\
\hline eff $f_{\text {ch }}$ & 0.5 & ef $f_{G T H}$ & 0.9 \\
ef $f_{\text {heat }}$ & 0.19 & eff $f_{C H P}$ & 0.9 \\
eff $f_{\text {ETH }}$ & 0.9 & eff $f_{\text {re }}$ & 0.8 \\
\hline
\end{tabular}

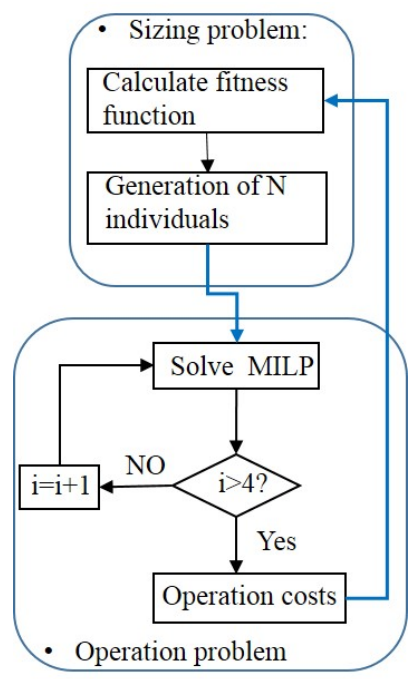

Figure 4: Simulation flow chart.

\subsection{Genetic algorithm based sizing results}

A genetic algorithm [30] is used to search for the sizing results. GA is based on the natural selection process similar to biological evolution, which includes three steps, mutation, crossover and selection. With these steps, a new population is generated. In the simulation, the population size is 20 , and the maximum number of iterations is 100 . In the example, there are 13 nodes, and at each node there are 7 components, so the number of variables is 91 . Each population gives the 91 values of each component, then the operation optimization problem is run. Based on the operation results (load shedding) and investment costs, the population is updated.

Tab. 6 shows the results of case 1. Tab. 7 shows the results of case 2. Tab. 8 shows the results of case 3. The unit of each component (PV panels, fuel cell, electrolyzer, ETH, GTH, CHP) in each table is $M W$, and the unit of $\mathrm{H}_{2}$ tanks is $M W h$.

Table 6: Case 1 results

\begin{tabular}{cccccccc}
\hline Node & $P_{P V}$ & $P_{f c}^{\max }$ & $P_{\text {ele }}^{\max }$ & $P_{E T H}^{\max }$ & $P_{G T H}^{\max }$ & $P_{C H P}^{\max }$ & $C_{g s}$ \\
\hline 1 & 7.10 & 2.41 & 0.21 & 0.29 & 0.72 & 3.33 & 84.77 \\
2 & 2.53 & 0.60 & 0.73 & 3.53 & 1.52 & 0.72 & 57.99 \\
3 & 4.77 & 0.02 & 0.95 & 1.64 & 3.49 & 0.39 & 4.91 \\
4 & 3.13 & 2.60 & 4.26 & 0.38 & 0.32 & 0.60 & 63.94 \\
5 & 3.53 & 0.01 & 2.95 & 2.55 & 2.72 & 1.01 & 89.28 \\
6 & 8.16 & 4.45 & 1.40 & 0.08 & 3.14 & 0.48 & 89.50 \\
7 & 5.91 & 1.92 & 2.67 & 0.04 & 3.65 & 4.59 & 13.97 \\
8 & 2.29 & 0.20 & 0.89 & 2.50 & 0.03 & 0.23 & 19.34 \\
9 & 3.90 & 1.47 & 3.66 & 2.80 & 0.16 & 1.08 & 76.84 \\
10 & 6.03 & 3.11 & 1.08 & 2.76 & 1.71 & 3.08 & 15.64 \\
11 & 4.79 & 0.81 & 3.09 & 1.72 & 0.98 & 3.97 & 78.53 \\
12 & 6.01 & 3.96 & 1.13 & 4.70 & 2.16 & 2.94 & 30.58 \\
13 & 2.65 & 2.20 & 1.78 & 2.24 & 3.41 & 0.07 & 50.46 \\
\hline Total & 60.78 & 23.76 & 24.80 & 25.23 & 24.00 & 22.50 & 675.76 \\
\hline
\end{tabular}

Table 7: Case 2 results

\begin{tabular}{cccccccc}
\hline \multirow{2}{*}{ Node } & $P_{P V}$ & $P_{f c}^{\max }$ & $P_{\text {ele }}^{\max }$ & $P_{E T H}^{\max }$ & $P_{G T H}^{\max }$ & $P_{C H P}^{\max }$ & $C_{g s}$ \\
\hline 1 & 0.00 & 0.31 & 1.16 & 2.73 & 1.44 & 3.89 & 77.93 \\
2 & 0.00 & 1.65 & 0.27 & 1.38 & 4.35 & 3.42 & 18.82 \\
3 & 3.24 & 2.18 & 0.74 & 0.41 & 1.89 & 1.48 & 3.69 \\
4 & 6.96 & 0.09 & 0.01 & 3.60 & 4.98 & 0.38 & 18.97 \\
5 & 9.41 & 0.36 & 3.78 & 3.71 & 3.97 & 2.68 & 19.75 \\
6 & 0.00 & 2.79 & 4.00 & 1.12 & 2.97 & 1.01 & 82.38 \\
7 & 0.00 & 3.15 & 0.76 & 3.43 & 2.53 & 0.32 & 62.97 \\
8 & 2.57 & 1.01 & 3.07 & 2.40 & 1.74 & 0.22 & 90.56 \\
9 & 7.74 & 2.51 & 0.93 & 0.71 & 4.35 & 2.10 & 52.50 \\
10 & 0.00 & 2.77 & 0.69 & 1.64 & 0.66 & 4.28 & 81.83 \\
11 & 3.03 & 0.19 & 4.17 & 3.26 & 2.66 & 2.58 & 81.33 \\
12 & 0.00 & 1.03 & 0.12 & 2.67 & 4.56 & 0.09 & 56.10 \\
13 & 0.00 & 3.95 & 4.46 & 2.09 & 0.37 & 0.99 & 47.04 \\
\hline Total & 32.95 & 22.00 & 24.15 & 29.15 & 36.46 & 23.43 & 693.85 \\
\hline
\end{tabular}

Fig. 5 shows a comparison of these three cases. In case 2, PV is limited to be installed at some nodes which are not the load demand central, so the PV output power must be transferred to load demand central based on the power transmission lines, but the capacity of power transmission lines will limit the 
Table 8: Case 3 results

\begin{tabular}{|c|c|c|c|c|c|c|c|}
\hline Node & $P_{P V}$ & $P_{f c}^{\max }$ & $P_{\text {ele }}^{\max }$ & $P_{E T H}^{\max }$ & $P_{G T H}^{\max }$ & $P_{C H P}^{\max }$ & $C_{g s}$ \\
\hline 1 & 3.19 & 0.56 & 0.83 & 3.16 & 1.08 & 1.06 & 13.99 \\
\hline 2 & 8.45 & 1.58 & 3.16 & 2.46 & 0.05 & 1.37 & 59.46 \\
\hline 3 & 8.25 & 2.95 & 3.24 & 4.62 & 0.84 & 3.79 & 83.83 \\
\hline 4 & 3.19 & 1.13 & 1.34 & 4.96 & 1.21 & 4.46 & 64.00 \\
\hline 5 & 6.26 & 1.65 & 3.51 & 0.14 & 3.96 & 1.22 & 7.27 \\
\hline 6 & 4.19 & 1.42 & 0.64 & 3.87 & 2.44 & 3.31 & 81.91 \\
\hline 7 & 6.13 & 1.69 & 0.20 & 1.58 & 3.48 & 0.34 & 64.67 \\
\hline 8 & 2.22 & 2.45 & 1.35 & 4.29 & 2.26 & 3.15 & 2.34 \\
\hline 9 & 5.40 & 0.81 & 4.09 & 0.85 & 0.28 & 1.11 & 79.54 \\
\hline 10 & 4.20 & 2.58 & 1.49 & 2.63 & 0.25 & 0.33 & 77.67 \\
\hline 11 & 4.94 & 0.67 & 4.09 & 3.78 & 3.96 & 4.59 & 95.33 \\
\hline 12 & 6.79 & 1.55 & 3.06 & 2.67 & 1.00 & 1.34 & 59.40 \\
\hline 13 & 6.06 & 3.70 & 0.97 & 0.22 & 0.40 & 1.27 & 1.78 \\
\hline Total & 69.27 & 22.75 & 27.96 & 35.23 & 21.20 & 27.32 & 691.20 \\
\hline
\end{tabular}

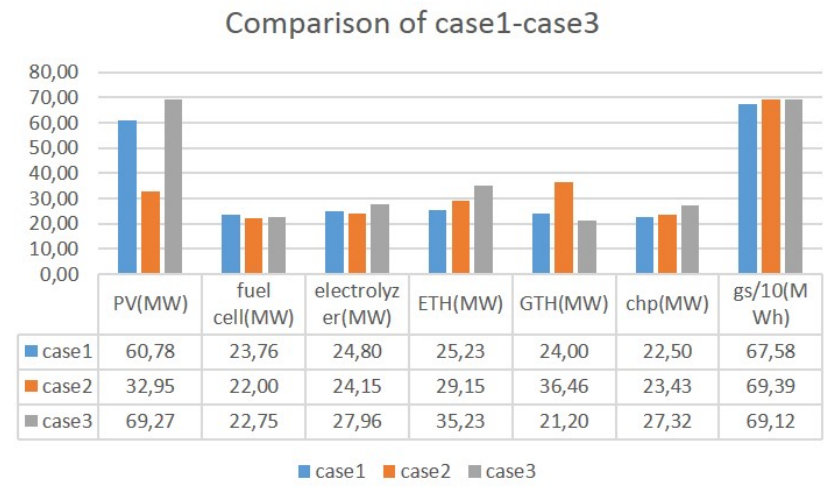

Figure 5: Comparison of the three cases.

transfered power. The installed PV power is smaller than that in case 1 (decreased by 50\%). This leads to a smaller capacity for the electrolyzer, which is used to store surplus PV output, and decreases by $3 \%$. The smaller capacity of PV leads to a larger capacity for the $\mathrm{H}_{2}$ tanks (increases by $2 \%$ ) and the CHP (increases by 4\%). The smaller capacity for the electrolyzer leads to a larger capacity for the ETH (increases by $15 \%$ ) because both devices are used to consume the electricity, and the surplus energy can either be stored in tanks through the" electrolyzer or through the ETH to supply the heating demand.

Comparing case 1 and case 3, it can be seen that in case 3, the capacity of PV is larger than that in case 1 (increases by $14 \%$ ). This is because the hydrogen storage system is competi-554 tive and can be used frequently. This is due to the reduction in ${ }_{555}$ the investment cost of the fuel cell and the electrolyzer, which ${ }_{556}$ makes the hydrogen storage more competitive. Then more $\mathrm{PV}_{557}$ panels can be installed, which leads to a larger capacity for the ${ }_{558}$ electrolyzer (increases by $13 \%$ ). More power can in turn be ${ }_{559}$ produced by $\mathrm{PV}$, which leads to a larger capacity for the $\mathrm{ETH}_{560}$ (increases by $40 \%$ ). A larger capacity for the ETH also leads to ${ }_{561}$ a smaller GTH (decreases by 13\%).

Comparing these three cases, it can be seen that the sizing ${ }_{563}$ results of PV, ETH, GTH, and CHP change, obviously. This is 564 because their costs are more competitive than that of the fuel ${ }_{565}$ cell and the electrolyzer, which has a larger ability to minimize the objective function.

Based on the above simulation results, it can be seen that PV panels' location and the investment cost of hydrogen storage system are important parameters to influence the sizing values of each component.

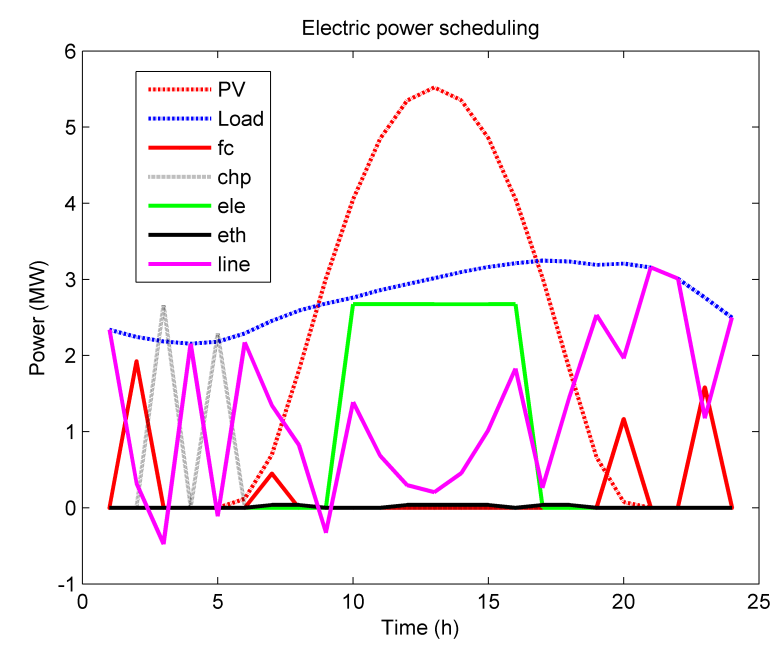

Figure 6: Electric power scheduling at node 7 (line L6).

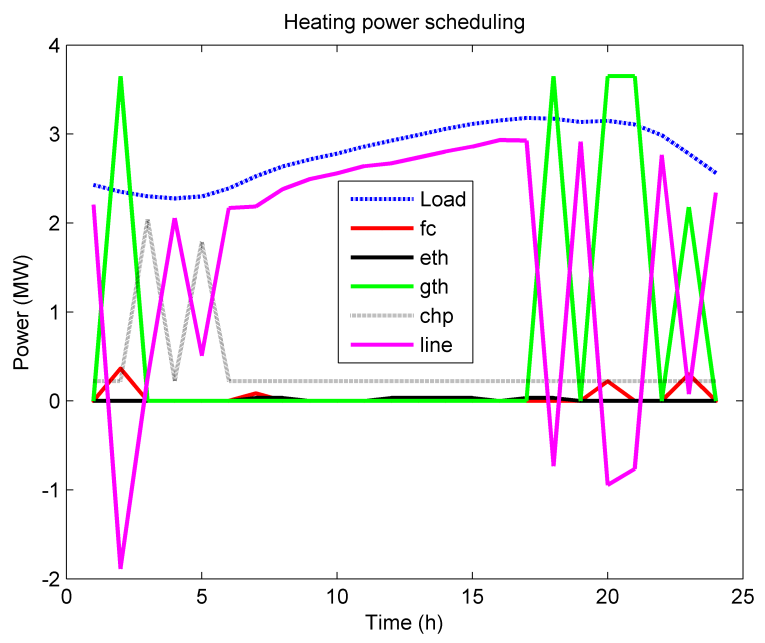

Figure 7: Heating power scheduling at node 7 (line L6).

Figs. 6, 7, 8, 9 show one day scheduling results of the three energy systems in a typical spring day. In Fig. 6, at node 7, electric energy is exchanged with the other nodes through power line L6. During the night, the fuel cell and CHP produce electricity to supply the loads. During the day, PV and imported energy are used to supply the loads. The electrolyzer is used to store the surplus energy. In Fig. 7, the CHP and GTH produce the main heat energy, and the fuel cell and ETH produce the remaining heat. Imported/exported heating energy through pipeline 6 is also important to keep the energy balance at node 7. Fig. 8 shows that gas imports through gas pipeline 6 are the main method to supply gas loads at node 7 . Fig. 9 shows the 


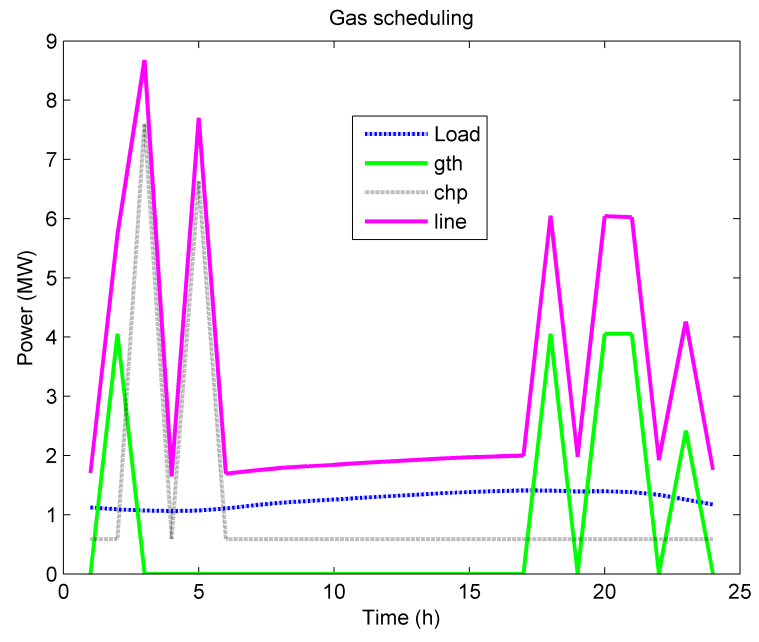

Figure 8: Gas scheduling at node 7 (line L6).

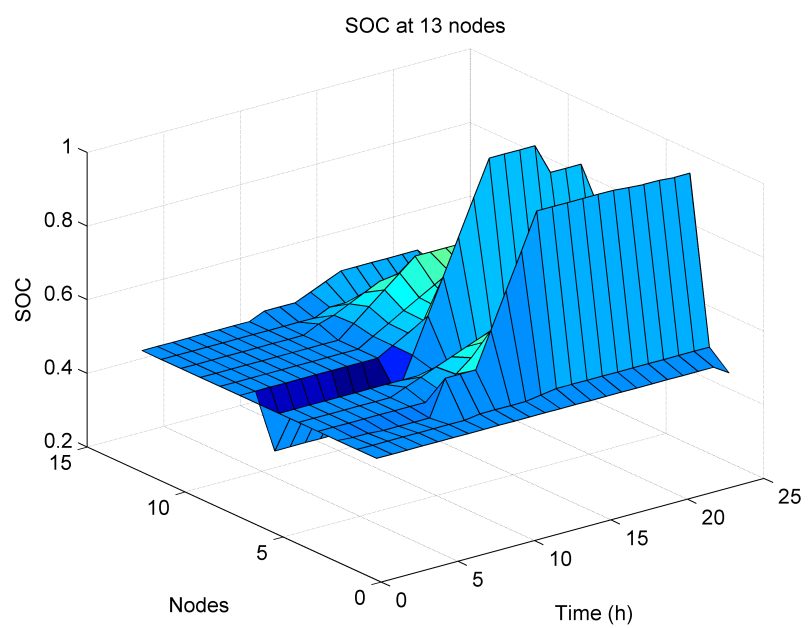

Figure 9: SOC at 13 nodes.

graph is described using the betweenness centrality value [35] of the node.

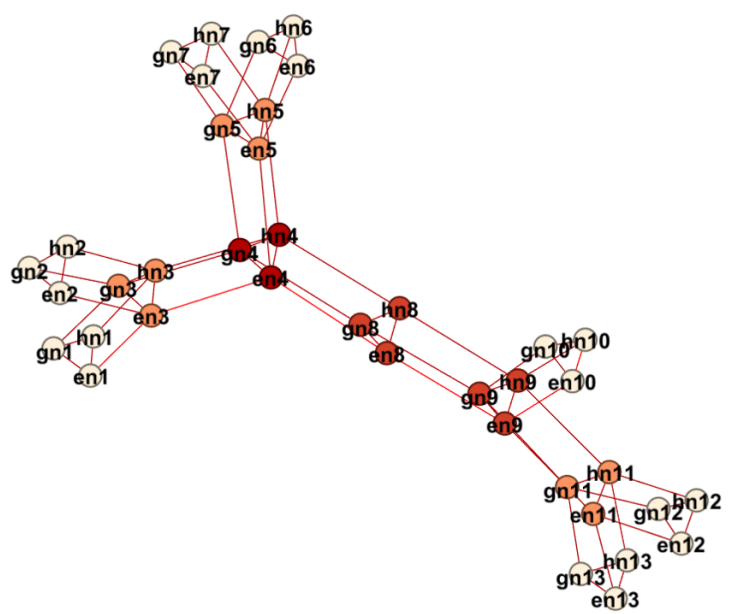

Figure 10: Graph structure of the 13-node hybrid network.

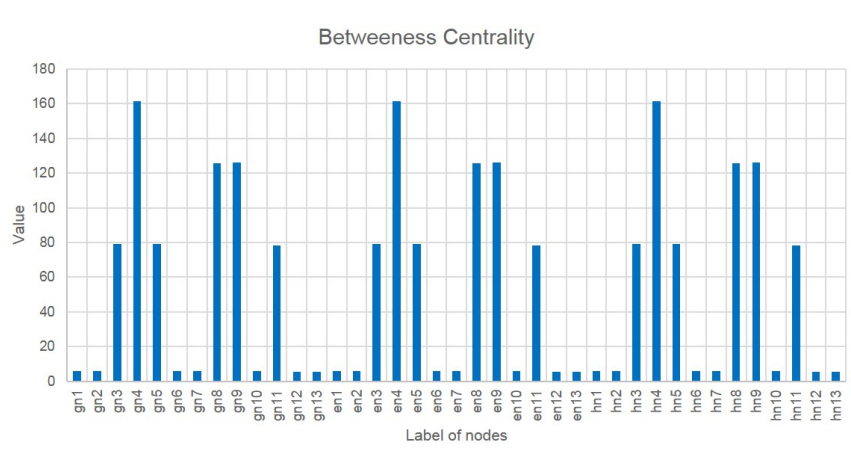

Figure 11: Betweenness centrality of the 13-node hybrid network. state of hydrogen tanks at all nodes. It can be seen that the storage system can be used to keep the power balance in the whole ${ }_{589}$ system: through the fuel cell, hydrogen tanks can produce elec- ${ }_{590}$ tricity and heat to supply the load demand, and through the elec- $-_{591}$ trolyzer, the surplus electricity can be stored in hydrogen tanks ${ }_{592}$ using $\mathrm{H}_{2}$.

From the scheduling results, the output of some power de- ${ }_{594}^{599}$ vices change fast, especially the lines. For example, in Fig. 7, ${ }_{595}$ at $2 \mathrm{am}$, the heat pipeline exports heating energy, but at $3 \mathrm{am}$, it ${ }_{596}$ switches to imports. The reason for this phenomenon is that the ${ }_{597}$ ramp up and ramp down constraints of all components are not ${ }_{598}$ limited.

\subsection{Influence of contingencies on the sizing results}

Based on section 3.3, the worst case can be obtained using 602 graph theory. For this 13-node hybrid network system, the rel-603 ative importance of each node is ranked. The case where the 604 most important node is destroyed under the contingency event 605 is the worst case. The relative importance of each node in the 606
Fig. 10 shows the graph connection of the 13-node hybrid network. Fig. 11 shows the betweenness centrality of the 13node hybrid network. It can seen that the most important node of the whole system is node 4 . The worst case for this network is thus when the connections between node 4 and the other nodes are removed.

As the failure probability of gas pipelines and heat pipelines are much smaller than that of overhead electric power lines [5], for the worst case, only the removal of electric power lines is considered. Then, the sizing problem needs to consider eight cases : the normal condition with four typical days of each season, and the worst case condition with four typical days. Tab. 9 shows the sizing results of the whole system when the electric connections between node 4 and the other nodes are removed, namely, by removing electric lines en $3 \leftrightarrow e n 4, e n 5 \leftrightarrow e n 4$, $e n 8 \leftrightarrow e n 4$. This case is defined as case 4 .

Fig. 12 shows a comparison of results for case 1 and case 4. It can be seen that: 1) at node 4, because the electric loads cannot import/export energy from/to the other nodes, so the capacity of PV and fuel cell is larger than that in case 1 (they increase by $12 \%$ and $11 \%$ respectively); 2) on the 


\begin{tabular}{|c|c|c|c|c|c|c|c|}
\hline Node & $P_{P V}$ & $P_{f c}^{\max }$ & $P_{\text {ele }}^{\max }$ & $P_{E T H}^{\max }$ & $P_{G T H}^{\max }$ & $P_{C H P}^{\max }$ & $C_{g s}$ \\
\hline 1 & 5.55 & 0.01 & 2.83 & 2.55 & 0.33 & 3.56 & 49.85 \\
\hline 2 & 5.58 & 2.02 & 3.42 & 0.74 & 1.62 & 0.21 & 32.59 \\
\hline 3 & 3.98 & 0.91 & 2.01 & 4.44 & 1.88 & 0.36 & 31.51 \\
\hline 4 & 7.30 & 2.72 & 4.83 & 4.67 & 0.20 & 0.22 & 12.83 \\
\hline 5 & 6.05 & 3.71 & 0.37 & 1.88 & 1.22 & 1.25 & 87.38 \\
\hline 6 & 7.25 & 1.67 & 2.00 & 0.77 & 1.77 & 2.37 & 56.29 \\
\hline 7 & 4.09 & 4.04 & 3.76 & 3.95 & 3.19 & 1.29 & 61.96 \\
\hline 8 & 3.92 & 1.76 & 1.37 & 3.09 & 3.02 & 2.91 & 25.46 \\
\hline 9 & 6.03 & 3.45 & 3.49 & 4.73 & 1.69 & 1.60 & 19.71 \\
\hline 10 & 4.86 & 0.52 & 0.25 & 3.81 & 0.62 & 1.59 & 64.03 \\
\hline 11 & 2.09 & 0.87 & 3.21 & 4.10 & 4.95 & 3.81 & 27.16 \\
\hline 12 & 3.45 & 4.12 & 2.96 & 4.20 & 1.91 & 0.93 & 68.01 \\
\hline 13 & 7.69 & 0.27 & 2.68 & 2.43 & 3.81 & 1.68 & 3.89 \\
\hline Total & 67.85 & 26.07 & 33.19 & 41.37 & 26.20 & 21.78 & 540.66 \\
\hline
\end{tabular}

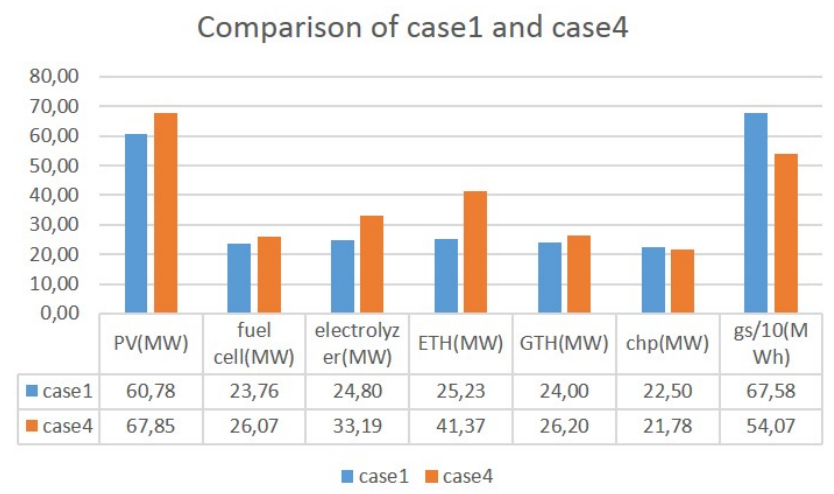

Figure 12: Comparison of case 1 and case 4.

other hand, this worst case divides the electric supply net ${ }^{660}$ work into four parts: $\{e n 1, e n 2, e n 3\},\{e n 4\},\{e n 5, e n 6, e n 7\}$, and ${ }^{661}$ $\{e n 8, e n 9$, en $10, e n 11$, en $12, e n 13\}$. Each part cannot receive ${ }^{662}$ electric power from the other parts through electric power lines, ${ }_{663}$ which means that the important task of keeping electric power ${ }_{664}$ balance is taken on by the fuel cell, the CHP device (the main ${ }_{655}$ controllable power sources) and PV panels. Larger PV panels ${ }_{666}$ lead to a larger capacity of electrolyzer (increases by 34\%) and ETH (increases by 64\%) to consume the surplus energy.

The above simulation shows that the structure of the whole system also influences the sizing results of each component. This is because the interconnection structure of the system can influence the energy flow in the whole system, which will then influence the utilization of the power devices, and at last, the sizing results will be different.

\subsection{Discussion}

Case 1 to case 3 show that the PV panels location and investment cost of hydrogen storage system influence the sizing value of each component. When the installed capacity of PV panels is reduced by $50 \%$, the capacity of the electrolyzer decreases by $3 \%$, capacity for the $\mathrm{H}_{2}$ tanks increases by $2 \%$, the CHP increases by $4 \%$, and ETH increases by $15 \%$. When the 667 investment costs of the fuel cell and the electrolyzer decrease 668 by $50 \%$, the capacity of PV increases by $14 \%$, the electrolyzer increases by $13 \%$, ETH increases by $40 \%$, and GTH decreases by $13 \%$.

To resist to contingency events, betweenness centrality is used to find the most important node (worst case). The simulation results (case 4) show that the controllable power sources (fuel cell, CHP), $\mathrm{PV}$ panels and the $\mathrm{H}_{2}$ tanks are the main components to ensure the system power balance. The capacity of PV and fuel cell increase by $12 \%$ and $11 \%$, and the electrolyzer increases by $34 \%$ while the ETH increases by $64 \%$. After the hybrid network is damaged by contingency events, the whole system is divided into small parts, namely, smaller 'islanded' microgrids. In each part, the main controllable power sources are the fuel cell and CHP. So the size of the PV panels and $\mathrm{H}_{2}$ tanks is important to enable the whole system to operate normally.

\section{Simulation results for Case II}

In this section, a benchmark hybrid gas/electricity/heat system is presented. The electricity network is the IEEE 30-node network [37] shown in Fig. 13. At nodes e1 and e2, two gas generators are connected. MG1, MG2, MG3 and MG4 are connected at nodes e23, e17, e14 and e7, respectively. The gas network is a 20-node system, whose parameters can be found in $[38,39]$, as shown in Fig. 14. The gas generators are connected at nodes $\mathrm{g} 12$ and $\mathrm{g} 19$. The heating source is supplied by gas at nodes g11, g12 and g14. MG1, MG2, MG3 and MG4 are connected at nodes g7, g6, g15 and g10, respectively. The heating network is a 14-node system [37], shown in Fig. 15. Nodes $\mathrm{h} 1$ and $\mathrm{h} 6$ and h11 are heating sources. MG1, MG2, MG3 and MG4 are connected at nodes h9, h10, h4 and h13, respectively. The configuration of this hybrid system is summarized in Tab. 10.

Two cases are simulated:

1. Case 5: normal operation state, namely, no connection node is removed;

2. Case 6: operation under contingency events, namely, the most important node is removed.

Table 10: Configuration of the studied system

\begin{tabular}{lccc}
\hline Unit & Electrical bus & Gas node & Heat node \\
\hline Generator 1 & e1 & $\mathrm{g} 12$ & - \\
Generator 2 & $\mathrm{e} 2$ & $\mathrm{~g} 19$ & - \\
Heating 1 & - & $\mathrm{g} 14$ & $\mathrm{~h} 1$ \\
Heating 6 & - & $\mathrm{g} 12$ & $\mathrm{~h} 6$ \\
Heating 11 & - & $\mathrm{g} 11$ & $\mathrm{~h} 11$ \\
MG1 & $\mathrm{e} 23$ & $\mathrm{~g} 7$ & $\mathrm{~h} 9$ \\
MG2 & $\mathrm{e} 17$ & $\mathrm{~g} 6$ & $\mathrm{~h} 10$ \\
MG3 & $\mathrm{e} 14$ & $\mathrm{~g} 15$ & $\mathrm{~h} 4$ \\
MG4 & $\mathrm{e} 7$ & $\mathrm{~g} 10$ & $\mathrm{~h} 13$ \\
\hline
\end{tabular}

The sizing results for these four MG are shown in Tab. 11 . Figs. 16, 17, 18, and 19 show one day scheduling results of 


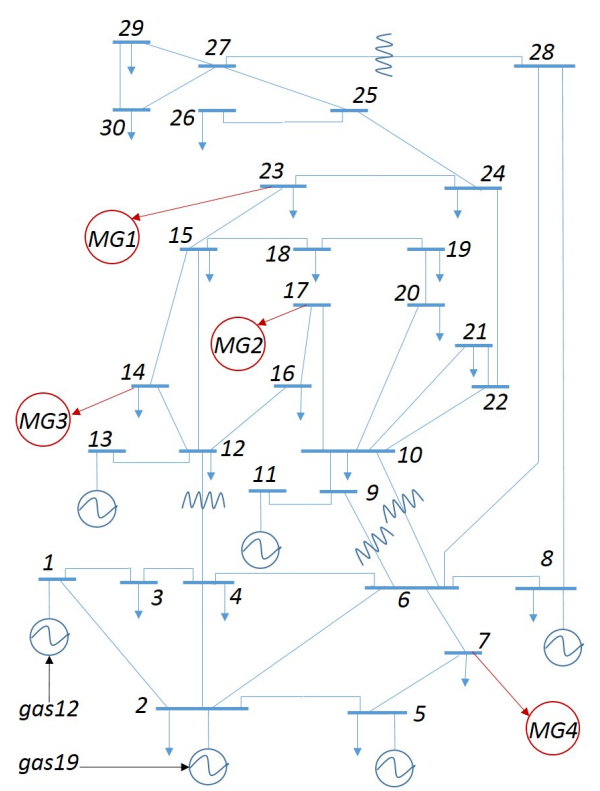

Figure 13: IEEE 30-node network.

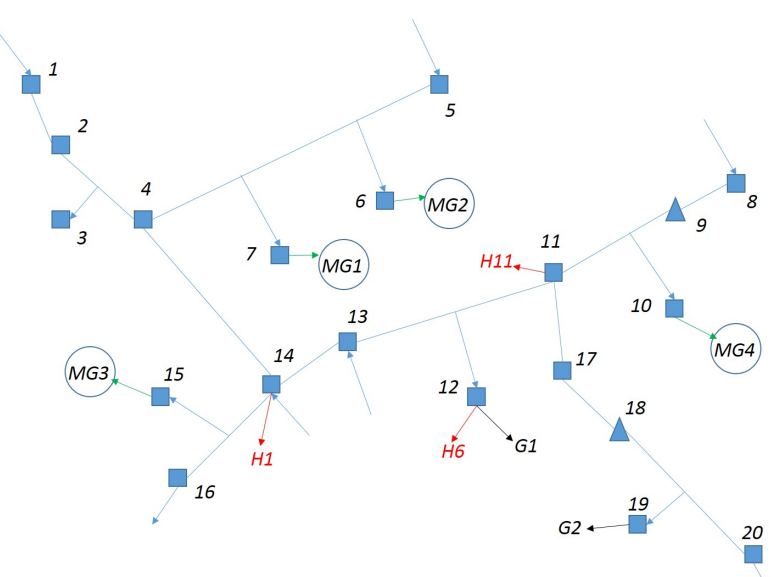

Figure 14: Gas 20-node network.

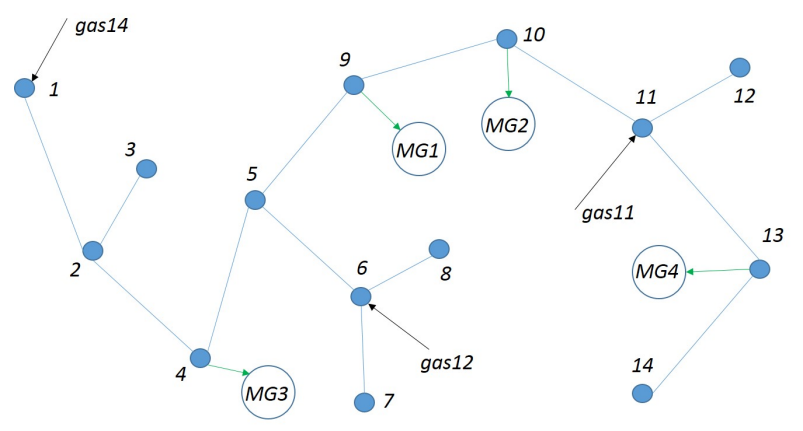

Figure 15: Heating 14-node network.
MG3 in a typical spring day. Figs. 20 and 21 show the gas flow in the gas supply system and the heat flow in the heating supply ${ }_{679}$ system.

The structure of this hybrid system is then analyzed to obtain 681
Table 11: Case II results

\begin{tabular}{lcccccccc}
\hline Node & $P_{P V}$ & $P_{f c}^{\max }$ & $P_{\text {ele }}^{\max }$ & $P_{E T H}^{\max }$ & $P_{G T H}^{\max }$ & $P_{C H P}^{\max }$ & $C_{g s}$ \\
\hline MG1 & 3.25 & 0.97 & 1.90 & 1.21 & 3.78 & 0.88 & 3.02 \\
MG2 & 3.75 & 0.20 & 3.22 & 4.40 & 1.07 & 1.32 & 0.68 \\
MG3 & 4.29 & 2.40 & 0.07 & 1.73 & 0.16 & 0.73 & 2.87 \\
MG4 & 3.60 & 0.46 & 1.57 & 4.89 & 0.21 & 0.90 & 4.02 \\
\hline Total & 14.89 & 4.03 & 6.75 & 12.24 & 5.21 & 3.82 & 10.59
\end{tabular}

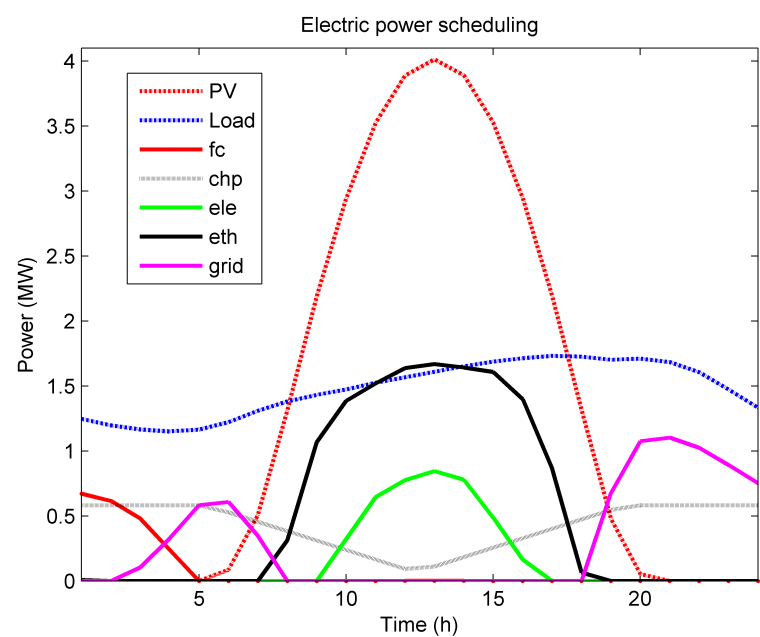

Figure 16: Electric power scheduling in MG 3.

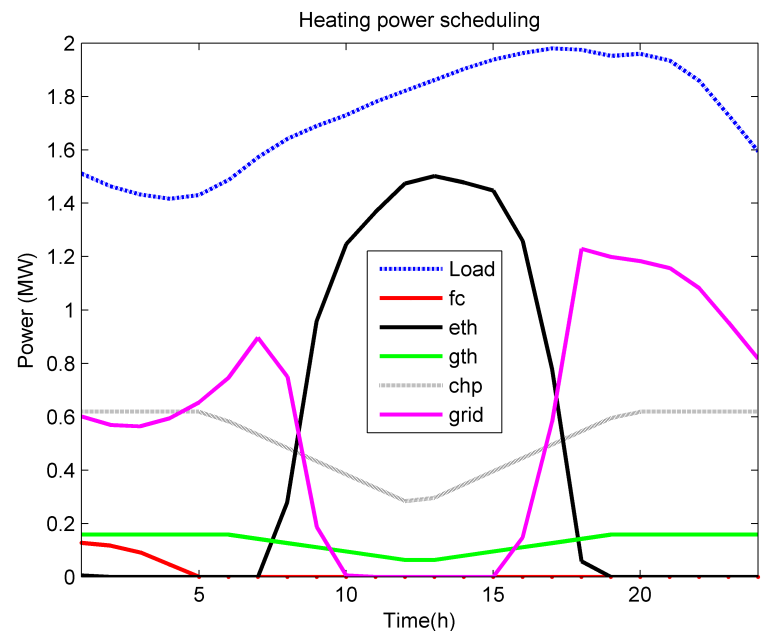

Figure 17: Heating power scheduling in MG 3. the worst case based on graph theory, as for case I. Fig. 22 shows the graph structure of the hybrid system. Fig. 23 then shows the betweenness centrality, which shows that the most important node is e6 (electrical network node 6). The worst case of this hybrid network is then defined, which is when the connections between node 6 and the other nodes are removed. Here, for the operation problem, 8 cases are considered: the normal condition with four typical days of each season, and the worst case condition with four typical days. 


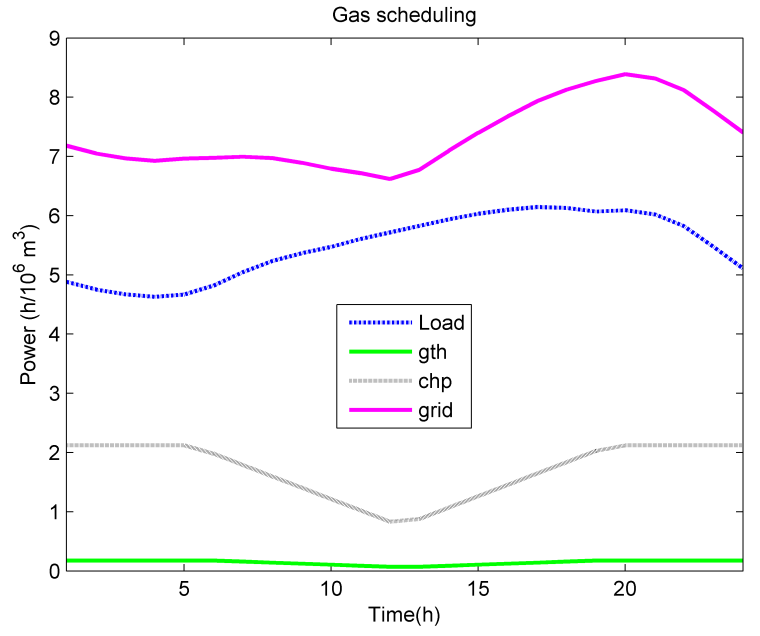

Figure 18: Gas scheduling in MG 3.

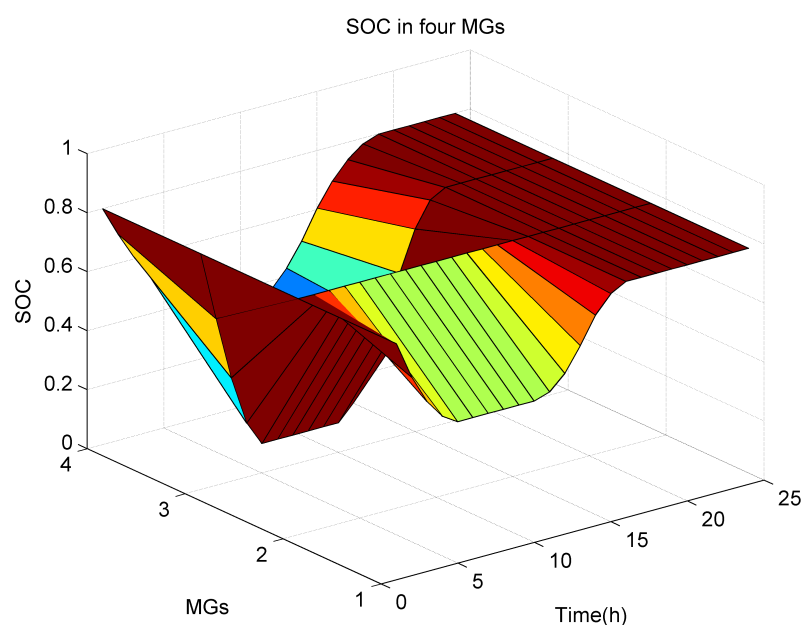

Figure 19: SOC in four MGs.

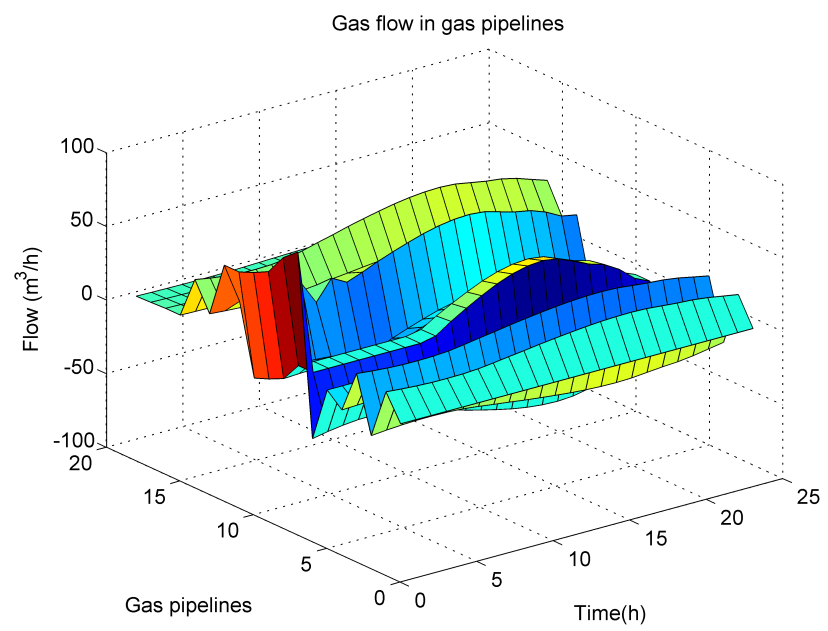

Figure 20: Gas flow in gas system.

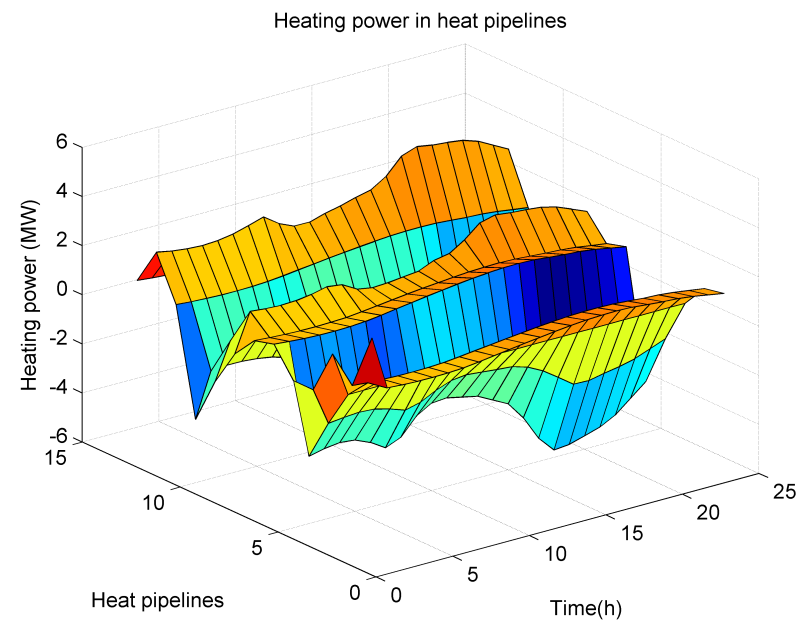

Figure 21: Heating flow in heat system.

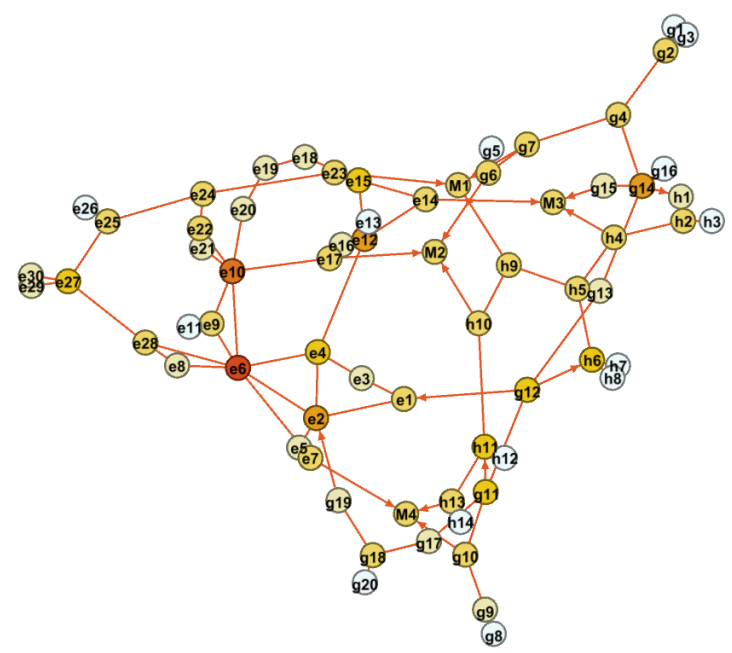

Figure 22: Graph structure of the hybrid system.

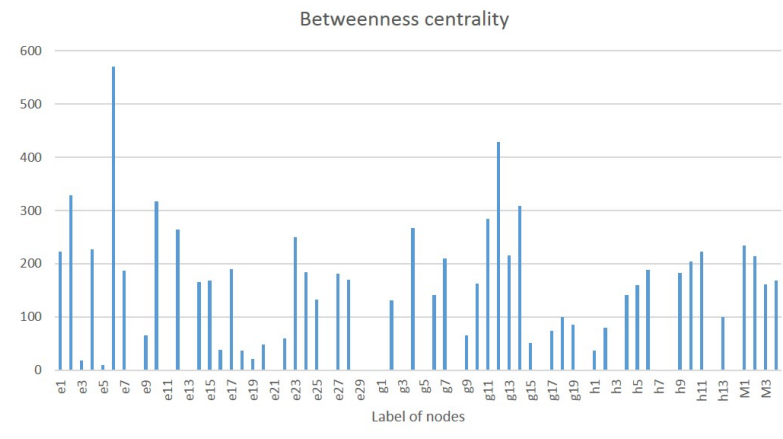

Figure 23: Betweenness centrality of the hybrid system.

Tab. 12 shows the sizing results when the connections between node 6 and other nodes is removed, namely, remove $e 6 \leftrightarrow e 2, e 6 \leftrightarrow e 4, e 6 \leftrightarrow e 7, e 6 \leftrightarrow e 8, e 6 \leftrightarrow e 9, e 6 \leftrightarrow e 10$, and $e 6 \leftrightarrow e 28$. Fig. 24 shows the comparison of case 5 and case 6 . It can be seen that after considering the damage on the 


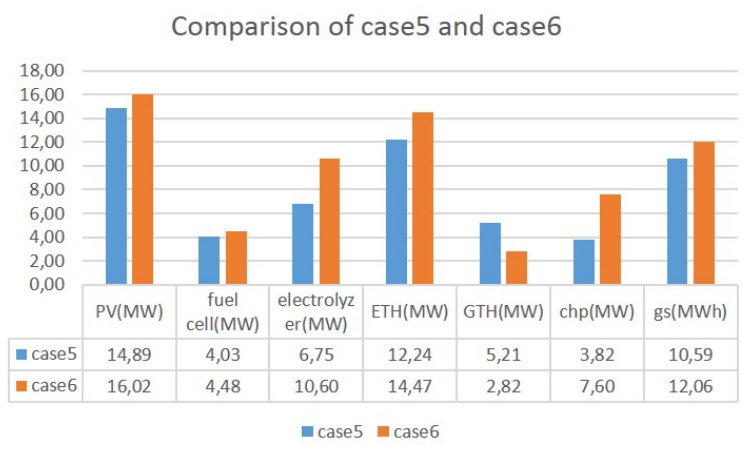

Figure 24: Comparison of case 5 and case 6.

\begin{abstract}
electrical network, more PV panels (increased by $8 \%$ ), fuel cell (increases by 11\%) and CHP are needed to supply the electricity ${ }_{733}$ demands in MG. The total sizing value of the GTH is decreased, but the sizing value of the ETH is increased by $18 \%$, because the ETH is used to fill up the position of the GTH to supplement the remaining heating demands. The total volume of hydrogen ${ }_{737}^{336}$ tanks is also increased by $14 \%$ to supply the electrical demands ${ }_{738}$ through fuel cells.
\end{abstract}

Table 12: Case II under disasters results

\begin{tabular}{lccccccc}
\hline Node & $P_{P V}$ & $P_{f c}^{\max }$ & $P_{\text {ele }}^{\max }$ & $P_{E T H}^{\max }$ & $P_{G T H}^{\max }$ & $P_{C H P}^{\max }$ & $C_{g s}$ \\
\hline MG1 & 4.40 & 2.23 & 0.03 & 4.12 & 0.66 & 3.54 & 2.85 \\
MG2 & 3.62 & 1.03 & 3.89 & 2.98 & 1.22 & 0.94 & 3.75 \\
MG3 & 4.00 & 0.36 & 4.05 & 3.93 & 0.37 & 0.75 & 3.87 \\
MG4 & 4.01 & 0.85 & 2.62 & 3.45 & 0.57 & 2.38 & 1.58 \\
\hline Total & 16.02 & 4.48 & 10.60 & 14.47 & 2.82 & 7.60 & 12.06
\end{tabular}

\section{Conclusion}

In this paper, a co-optimization method is presented to size $_{754}^{75}$ distributed generation in a hybrid gas/electricity/heat network. 755 Mixed integer linear programming is used to control the oper-756 ation of the whole system, which aims to minimize load shed ${ }^{758}$ ding. GA is used to search for the sizing values of each com $^{-559}$ ponent. Case 1 and case 2 show that the PV panels location760 influence the sizing results of each component. This is because ${ }^{761}$ the PV panels operating as uncontrollable power sources $\operatorname{ar}_{763}^{762}$ playing an important role to ensure the power balance of the ${ }_{764}$ whole system. The controllable power devices are all operating 765 encompassly the PV panels. At last, with different capacities ${ }^{766}$ of PV panels, the sizing results of each component are also $\operatorname{dif}^{-767}$ ferent. When the installed capacity of PV panels is reduced by 769 $50 \%$, the capacity of the electrolyzer decreases by $3 \%$, the ca- -770 pacity for the $\mathrm{H}_{2}$ tanks increases by $2 \%$ and the CHP increases ${ }_{772}^{771}$ by $4 \%$ while the ETH increases by $15 \%$.

Case 1 and case 3 show that the investment cost of the hy-774 drogen storage system also influences the sizing results. This is ${ }^{775}$ because the investment costs impact the competitivity of each ${ }_{777}^{776}$ component to minimize the objective function. When the in ${ }^{777}$ vestment cost of the fuel cell and the electrolyzer decrease by
$50 \%$, the capacity of PV increases by $14 \%$, the electrolyzer increases by $13 \%$, ETH increases by $40 \%$, and the GTH decreases by $13 \%$.

A new method based on betweenness centrality is then proposed to find the worst case under contingency events. Case 4 shows that the controllable power sources (fuel cell, CHP), PV panels and $\mathrm{H}_{2}$ tanks are the main factors that influence whether the whole system can operate normally or not. After considering the worst case contingency event, for case 4 , the capacity of PV and fuel cell increase by $12 \%$ and $11 \%$, and the electrolyzer increases by $34 \%$, while the ETH increases by $64 \%$.

At last, an IEEE30 + Gas20 + Heat14-node network is tested (case 5 and case 6 ). Case 6 shows that the structure of the power system influences the energy exchanges between the grid and MG, and influence the sizing values in each MG. The results indicate that more power is imported from the gas network when power supply network exports are limited. After considering the worst case contingency event, for case II, the capacity of PV and fuel cell increase by $8 \%$ and $11 \%$, and the electrolyzer increases by $57 \%$ while the ETH increases by $18 \%$.

This co-optimization method can be used as a guidance for utility companies to build large nodes hybrid gas/electricity/heat supply networks.

\section{References}

[1] J. Mitra, M. R. Vallem, C. Singh, Optimal deployment of distributed generation using a reliability criterion, IEEE Transactions on Industry Applications 52 (3) (2016) 1989-1997.

[2] L. B. Jaramillo, A. Weidlich, Optimal microgrid scheduling with peak load reduction involving an electrolyzer and flexible loads, Applied Energy 169 (Supplement C) (2016) 857 - 865. doi:https://doi.org/10.1016/j.apenergy.2016.02.096.

[3] B. Li, R. Roche, D. Paire, A. Miraoui, Sizing of a stand-alone microgrid considering electric power, cooling/heating, hydrogen loads and hydrogen storage degradation, Applied Energy 205 (2017) 1244 - 1259. doi:https://doi.org/10.1016/j.apenergy.2017.08.142.

[4] A. Sheikhi, S. Bahrami, A. M. Ranjbar, An autonomous demand response program for electricity and natural gas networks in smart energy hubs, Energy 89 (2015) 490-499.

[5] B. Li, R. Roche, A. Miraoui, System resilience improvement using multiple energy supply systems under natural disasters, in: Industrial Electronics Society, IECON 2016-42nd Annual Conference of the IEEE, IEEE, 2016, pp. 3912-3917.

[6] I. G. Moghaddam, M. Saniei, E. Mashhour, A comprehensive model for self-scheduling an energy hub to supply cooling, heating and electrical demands of a building, Energy 94 (2016) 157-170.

[7] G. M. Kopanos, M. C. Georgiadis, E. N. Pistikopoulos, Energy production planning of a network of micro combined heat and power generators, Applied energy 102 (2013) 1522-1534.

[8] E. Shirazi, S. Jadid, Cost reduction and peak shaving through domestic load shifting and ders, Energy 124 (2017) 146-159.

[9] J. Silvente, A. M. Aguirre, M. A. Zamarripa, C. A. Méndez, M. Graells, A. Espuña, Improved time representation model for the simultaneous energy supply and demand management in microgrids, Energy 87 (2015) 615-627.

[10] J. Silvente, L. G. Papageorgiou, An milp formulation for the optimal management of microgrids with task interruptions, Applied Energy 206 (2017) 1131-1146.

[11] D. Zhang, S. Evangelisti, P. Lettieri, L. G. Papageorgiou, Economic and environmental scheduling of smart homes with microgrid: Der operation and electrical tasks, Energy Conversion and Management 110 (2016) 113-124.

[12] gurobi, gurobi (2017). URL http://www.gurobi.com/resources/getting-started/mip-basics 
[13] P. Prakash, D. K. Khatod, Optimal sizing and siting techniques for dis-85 tributed generation in distribution systems: A review, Renewable and Sus-852 tainable Energy Reviews 57 (2016) 111-130.

14] A. R. Jordehi, Allocation of distributed generation units in electric power854 systems: A review, Renewable and Sustainable Energy Reviews 56855 (2016) 893-905.

[15] J. H. Roh, M. Shahidehpour, Y. Fu, Market-based coordination of trans-85 mission and generation capacity planning, IEEE Transactions on Power858 Systems 22 (4) (2007) 1406-1419.

[16] A. Khodaei, M. Shahidehpour, Microgrid-based co-optimization of gen-860 eration and transmission planning in power systems, IEEE transactions 861 on power systems 28 (2) (2013) 1582-1590.

[17] A. Khodaei, S. Bahramirad, M. Shahidehpour, Microgrid planning under uncertainty, IEEE Transactions on Power Systems 30 (5) (2015) 2417 2425.

[18] A. Khayatian, M. Barati, G. J. Lim, Market-based and resilient coordinated microgrid planning under uncertainty, in: Transmission and Distribution Conference and Exposition (T\&D), 2016 IEEE/PES, IEEE, 2016, pp. $1-5$.

[19] R. Hemmati, H. Saboori, P. Siano, Coordinated short-term scheduling and long-term expansion planning in microgrids incorporating renewable energy resources and energy storage systems, Energy.

[20] Y. Yang, S. Zhang, Y. Xiao, Optimal design of distributed energy resource systems coupled with energy distribution networks, Energy 85 (2015) 433-448.

[21] O. Shaneb, G. Coates, P. Taylor, Sizing of residential $\mu$ chp systems, Energy and Buildings 43 (8) (2011) 1991-2001.

[22] Q. Zhu, X. Luo, B. Zhang, Y. Chen, Mathematical modelling and optimization of a large-scale combined cooling, heat, and power system that incorporates unit changeover and time-of-use electricity price, Energy Conversion and Management.

[23] L. Guo, W. Liu, J. Cai, B. Hong, C. Wang, A two-stage optimal planning and design method for combined cooling, heat and power microgrid system, Energy Conversion and Management 74 (2013) 433-445.

[24] A. Zidan, H. A. Gabbar, A. Eldessouky, Optimal planning of combined heat and power systems within microgrids, Energy 93 (2015) 235-244.

[25] C. Shao, M. Shahidehpour, X. Wang, X. Wang, B. Wang, Integrated planning of electricity and natural gas transportation systems for enhancing the power grid resilience, IEEE Transactions on Power Systems.

[26] X. Zhang, M. Shahidehpour, A. S. Alabdulwahab, A. Abusorrah, Security-constrained co-optimization planning of electricity and natural gas transportation infrastructures, IEEE Transactions on Power Systems 30 (6) (2015) 2984-2993.

[27] J. Qiu, Z. Y. Dong, J. H. Zhao, K. Meng, Y. Zheng, D. J. Hill, Low carbon oriented expansion planning of integrated gas and power systems, IEEE Transactions on Power Systems 30 (2) (2015) 1035-1046.

[28] C. Unsihuay-Vila, J. Marangon-Lima, A. Z. de Souza, I. J. Perez-Arriaga, P. P. Balestrassi, A model to long-term, multiarea, multistage, and integrated expansion planning of electricity and natural gas systems, IEEE Transactions on Power Systems 25 (2) (2010) 1154-1168.

[29] S. Mashayekh, M. Stadler, G. Cardoso, M. Heleno, A mixed integer linear programming approach for optimal der portfolio, sizing, and placement in multi-energy microgrids, Applied Energy 187 (2017) 154-168.

[30] B. Li, R. Roche, A. Miraoui, Microgrid sizing with combined evolutionary algorithm and milp unit commitment, Applied Energy 188 (2017) $547-562$.

[31] S. Xinwei, H. Yingduo, Z. Shouzhen, J. Zheng, L. Qingsheng, N. Jing, Comprehensive power-supply planning for active distribution system considering cooling, heating and power load balance, Journal of Modern Power Systems and Clean Energy 3 (4) (2015) 485-493.

[32] B. Zeng, L. Zhao, Solving two-stage robust optimization problems using a column-and-constraint generation method, Operations Research Letters 41 (5) (2013) 457-461.

[33] Z. Wang, B. Chen, J. Wang, J. Kim, M. M. Begovic, Robust optimization based optimal dg placement in microgrids, IEEE Transactions on Smart Grid 5 (5) (2014) 2173-2182.

[34] W. Yuan, J. Wang, F. Qiu, C. Chen, C. Kang, B. Zeng, Robust optimization-based resilient distribution network planning against natural disasters, IEEE Transactions on Smart Grid 7 (6) (2016) 2817-2826.

[35] S. Chanda, A. K. Srivastava, Defining and enabling resiliency of electric distribution systems with multiple microgrids, IEEE Transactions on
Smart Grid 7 (6) (2016) 2859-2868.

[36] J. Löfberg, Automatic robust convex programming, Optimization methods and software 27 (1) (2012) 115-129.

[37] A. Shabanpour-Haghighi, A. R. Seifi, Simultaneous integrated optimal energy flow of electricity, gas, and heat, Energy Conversion and Management 101 (2015) 579-591.

[38] D. De Wolf, Y. Smeers, The gas transmission problem solved by an extension of the simplex algorithm, Management Science 46 (11) (2000) 1454-1465

[39] A. Martinez-Mares, C. R. Fuerte-Esquivel, A unified gas and power flow analysis in natural gas and electricity coupled networks, IEEE Transactions on Power Systems 27 (4) (2012) 2156-2166. 